\title{
Cyclometalated Iridium(III) Complexes for Life Science
}

Chiara Caporale and Massimiliano Massi*

Curtin Institute of Functional Molecules and Interfaces - Department of Chemistry, Curtin University, Kent Street, Bentley 6102 WA, Australia.

Corresponding author's email: $\underline{\text { m.massi@curtin.edu.au. }}$

\section{Abstract}

Photoluminescent cyclometalated iridium(III) complexes are now a well established class of organometallic compounds with advantageous potential applications in biology and life science. While these complexes, along with other luminescent transition metals and lanthanoid complexes, were initially proposed as alternative markers to organic fluorophores in the staining of cells, it is now apparent that their specific biological behaviour can make this class of compounds useful in a broader areas of life science such as imaging, sensing and therapy. The critical factors for the effective design of cyclometalated iridium(III) complexes with specific biological properties are still rather difficult to rationalize and often mainly rely of aspects such as the intrinsic charge of the complex, its lipophilicity and it aqueous solubility. This review overviews the area of cyclometalated iridium(III) complexes in biology, with an emphasis on comparing the various conditions that these compounds have been assessed for their biological potential, such as the specific tested 
cells lines, concentration of internalization, incubation time, and mechanism of cellular entrance.

Keywords: iridium; luminescence; imaging; therapy; cells; cytotoxicity

\section{Introduction}

Cellular imaging has become a very powerful tool in life science [1-4]. The technique allows the direct visualization of cells at subcellular resolution, and therefore it can be conveniently exploited to image the cell as a whole, specific subcompartments and organelles (such as nucleous, mitochondria, and lysosomes, for example), and even the presence and concentration of key biological and metabolic species [5-11].

While label-free techniques that exploits the autofluorescence of endogenous molecular species have been extensively developed [12-17], optical imaging commonly relies on the incubation of luminescent markers (often referred to as molecular probes or cellular imaging agents). The area of organic fluorophores for cellular imaging is certainly well advanced and in continuous evolution, and many probes that are now of fundamental importance for optical imaging have been developed for various applications within a cellular environment [18-23]. While these markers are certainly well established and essential in the field, for specific imaging conditions they might be associated with drawbacks that are intimately linked to the organic nature of these compounds.

Typically, luminescent organic molecules have rather small Stokes shifts, often resulting in a significant overlap between the absorption and emission spectral profiles 
$[24,25]$. Therefore, as the probe accumulates within a specific cellular compartment and its local concentration effectively increases, its brightness (defined as the product of molar absorptivity and photoluminescent quantum yield) can be reduced due to concentration quenching phenomena. As mentioned above, cells are inherently fluorescent due to the presence of photoactive endogenous compounds such as flavins, nicotinamides, and indole side group of tryptophan amino acids, for example [26-31]. If the excitation and emission profiles of the marker in use are in the same region of those of autofluorescent endogenous species, it might be difficult to discriminate between the two signals. Lastly, but potentially one of the most limiting drawbacks, is represented by the tendency of some organic molecules to undergo photobleaching [32-34]. This process occurs once the compound is excited to higher energy states, from which unwanted reactivity can occur destroying the emissive properties of the marker. It should be noted that some molecular probes can undergo extensive photobleaching within very short amount of time (less than one minute), limiting the usefulness of the probe for longer-time experiments in live cells.

In case one of more of the previously listed drawbacks are encountered, depending on the specific conditions used for the imaging experiments, it is essential to have alternative markers to overcome them. To fulfil this goal, luminescent transition metal complexes of low spin $d^{6}$ electronic configuration such a ruthenium(II), rhenium(I), and iridium(III), of $d^{8}$ electronic configuration such as gold(I) and platinum(II) [10,35-37], as well as lanthanoid complexes of visible emitters, such as $\mathrm{Eu}(\mathrm{III})$ and $\mathrm{Tb}(\mathrm{III})$, or NIR emitters, such as $\mathrm{Yb}(\mathrm{III})$ [38-42], have been investigated. All these complexes display favourable chemical characteristics and advantageous photophysical properties that make them ideal candidates for the development of complementary probes to organic fluorophores for applications in cellular imaging [43]. 
The transition metal complexes listed above are triplet state emitters, which makes them phosphorescent given that their ground state is of singlet spin multiplicity $[44,45]$. The energy stabilization on passing through a singlet to a triplet excited state, promoted by the strong spin-orbit coupling of the metal center, ensures that the Stokes shift is much larger when compared to fluorescent molecules. This larger shift results in a lack of overlap between the absorption and emission profiles, therefore limiting the extent of concentration quenching. The lanthanoid complexes also have quite large Stokes shift $[46,47]$, derived from the fact that their efficient excitation is obtained via the antenna effect, where the coordinated chromophoric ligand is photoexcited to its singlet manifold, undergoes intersystem crossing, and eventually transfers the energy to the respective emissive states of the lanthanoid cation $[48,49]$.

As radiative decay of transition metal complexes is forbidden by the spin selection rule, given the fact that there is a change in spin multiplicity on decaying from a triplet excited state to a singlet ground state, the characteristic excited state lifetime of these species is typically longer compared to organic fluorophores [50,51]. Transition metal complexes usually decay within a time range between hundreds of nanoseconds up to microseconds, whereas spin-allowed fluorescence from organic species typically occurs within few nanoseconds. Also in the case of lanthanoid complexes [47], $f-f$ interconfigurational electronic transitions are parity and often spin forbidden, resulting in elongated excited state lifetimes ranging between microseconds and milliseconds. A long excited state lifetime can be exploited to significantly reduce unwanted background autofluorescence using time-gated detection associated with microscopy techniques $[52,53]$. In fact, a time delay of few hundreds of nanoseconds would ensure that the luminescence signal coming from the cells is exclusively belonging to the metal centre 
probe, because autofluorescent processes are already fully completed. This aspect is especially useful when the excitation and emission profiles of the probe overlap with those of endogenous fluorescent species.

Depending on the specific chemical nature of the coordinated ligands, metal complexes of ruthenium(II), rhenium(I), iridium(III), gold(I) and platinum(II) can be quite kinetically inert, which favours lack of reactivity through ligand exchange that can potentially lead to cytotoxicity. On the other hand, the typical lability of lanthanoid cations is usually overcome by coordination with high denticity ligands, making the resulting complexes stabilized via the chelate effect. These design factors can also indeed aid in reducing photobleaching, thus making metal complexes viable molecular probes for longer timescale imaging with live cells without significant loss of photoluminescence $[37,39,51,54]$.

While they certainly possess advantageous photophysical properties, especially in the case of phosphorescent transition metals, it is essential to consider their ability to sensitize singlet oxygen [55-57]. Production of singlet oxygen within live cells can lead to extensive photocytotoxicity, even in cases when the metal complex is non cytotoxic when incubated within live cells that are kept in the dark without photoexcitation. In fact, this very characteristic has sparked the investigation of many metal complexes from cellular markers to phototherapeutic agents in the field of photodynamic therapy (PDT) [58-62].

Amongst the various metal complexes, cyclometalated iridium(III) species [63-69] have received extensive investigation for applications in life science. Typically, these complexes comprise an iridium(III) centre bound to two cyclometalated ligands such as phenylpyridine, and one bidentate ligand such as a diimine (although it is not uncommon to 
find two monodentate ligands). The chemical nature of this family of complexes can be readily tuned by chemical variations of the coordinated ligands, this allowing tuning of properties such as charge, lipophilicity, and solubility, as well as photoluminescent characteristics. In fact, it is known that iridium complexes can be tuned to be emissive across the entire range of the visible spectrum, from blue to red, and further in the nearinfrared region. Given this high versatility, it is not surprising that a large number of iridium complexes have been investigated for their potential application as cellular markers and therapeutic agents.

The strategies adopted to design iridium(III) complexes for life science can be broadly divided into two categories. Complexes can be bioconjugated to biological or targeting vectors, with the aim of inducing a specific biological behaviour. For example, the complex could be bioconjugated to target localization within a specific organelle such as mitochondria, to interact with specific biological species such as a proton in the measurement of intracellular $\mathrm{pH}$, or to sense and quantify the presence of specific analytes. The complexes can also be designed to exhibit a photophysical response that is able to be modulated by the targeted even, as for example in the case of fluorogenic turn-ON complexes or ratiometric complexes. On the other hand, the complexes might lack bioconjugation, and their biological behaviour can be investigated to elucidate a structureactivity profile. In this case, it becomes immediately apparent how a rationalization between structure and activity is quite complex to achieve, despite the fact that it would be extremely beneficial for the design of advanced and superior iridium complexes for targeted applications in life science. The main critical aspects that are typically invoked in structureactivity studies are charge, lipophilicity and solubility [70]. These are indeed very useful, but in general these considerations seems to be appropriate for small sub-libraries of complexes 
that have analogous chemical formulations. What constitute also a complication is the fact that very often the experimental conditions used by the research groups worldwide are very different, with variations occurring on the specific cells lines used, concentration, incubation time, imaging time, and imaging protocol. These aspects often lead to results that are not just dependent on the chemical nature and characteristics of the metal complex. Nonetheless, the field has rapidly broadened in the past decades from being just limited to cellular imaging. Perhaps, it would be essential to further refine the field to find a set of common protocols to screen the complexes and aid in further rationalization of structureactivity relationship?

This review presents a broad overview of the use of iridium complexes in life science, not only with a focus on the specific chemical nature examples of investigated cyclometalated iridium(III) complexes, but also trying to gather extended information of the various experimental conditions that these species have been used, all of which are summarized in Table 1, including determination of parameters such as lipophilicity and mechanism of cellular internalization when available. In structuring this review, the complexes have been grouped according to their specific localization, including cytoplasm, nucleous, lysosomes, mitochondria, and endoplasmic reticulum. 
Table 1. Summary of data and conditions for the cyclometalated iridium(III) complexes presented in this review.

\begin{tabular}{|c|c|c|c|c|c|c|c|c|c|c|c|c|}
\hline Organelle & Probe & Charge & Application & Cell lines ${ }^{\mathrm{a}}$ & Lipophilicity & $\begin{array}{l}\text { Incubation } \\
\text { time } e^{\mathrm{c}, \mathrm{d}, \mathrm{e}}\end{array}$ & Concentration & $\begin{array}{l}\text { Viability } \\
\text { dark }\end{array}$ & $\begin{array}{l}\text { Phototoxic } \\
\text { index }\end{array}$ & $\mathrm{IC}_{50}$ & $\begin{array}{l}\text { Uptake } \\
\text { mechanism } \\
\text { (method of } \\
\text { detection) }\end{array}$ & Ref \\
\hline \multirow{6}{*}{ 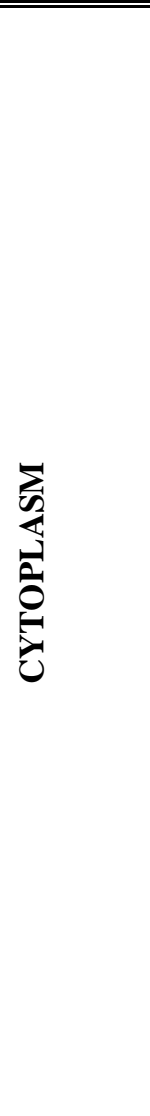 } & $1-2$ & Cationic & Bioimaging & $\begin{array}{l}\text { HeLa } \\
\text { MCF-7 } \\
\text { HCT-8 }\end{array}$ & - & $24 \mathrm{~h}$ & $100 \mu \mathrm{M}$ & $>90 \%$ & - & - & $\begin{array}{l}- \\
\text { (Fluorescent } \\
\text { intensity) }\end{array}$ & $\overline{[71]}$ \\
\hline & $3-6$ & Cationic & Bioimaging & $\begin{array}{l}\text { HeLa } \\
\text { MCF-7 } \\
\text { HCT-8 }\end{array}$ & - & $24 \mathrm{~h}$ & $100 \mu \mathrm{M}$ & $>90 \%$ & - & - & $\begin{array}{l}- \\
\text { (Fluorescent } \\
\text { intensity) }\end{array}$ & [63] \\
\hline & 7 & Neutral & $\begin{array}{l}\text { Ratiometric } \\
\text { probe }\end{array}$ & $\begin{array}{l}\mathrm{HeLa} \\
\mathrm{KB}\end{array}$ & - & $24 \mathrm{~h}$ & $100 \mu \mathrm{M}$ & $>90 \%$ & - & - & $\begin{array}{l}- \\
\text { (Fluorescent } \\
\text { intensity) }\end{array}$ & [72] \\
\hline & 8 & Neutral & $\begin{array}{l}\text { Photoswitcha } \\
\text { ble probe }\end{array}$ & KB & - & $24 \mathrm{~h}$ & $20 \mu \mathrm{M}$ & $>80 \%$ & - & - & $\begin{array}{l}- \\
\text { (Fluorescent } \\
\text { intensity) }\end{array}$ & [73] \\
\hline & 9 & Neutral & Bioimaging & $\mathrm{KB}$ & - & $8 \min ^{\mathrm{d}}$ & $2 \mathrm{mg} / \mathrm{mL}^{\mathrm{d}}$ & - & - & - & $\begin{array}{l}\text { - } \\
\text { (Fluorescent } \\
\text { intensity) }\end{array}$ & [74] \\
\hline & $\begin{array}{l}10 \mathbf{a}-\mathbf{c} \\
11 \mathbf{a}-\mathbf{b}\end{array}$ & $\begin{array}{l}\text { Neutral } \\
\text { Cationic }\end{array}$ & Bioimaging & $\begin{array}{l}\text { HeLa } \\
\text { A549 }\end{array}$ & $\begin{array}{l}1.28-1.57 \\
0.56-0.89\end{array}$ & $24 \mathrm{~h}$ & $20 \mu \mathrm{M}^{\mathrm{f}}$ & - & - & $\begin{array}{l}73-200 \\
50-120\end{array}$ & $\begin{array}{l}\text { Energy- } \\
\text { dependent } \\
\text { (flow }\end{array}$ & [75] \\
\hline
\end{tabular}




\begin{tabular}{|c|c|c|c|c|c|c|c|c|c|c|c|c|}
\hline & & & & & & & & & & & cytometry) & \\
\hline & 12 & Cationic & Ratiometric & HeLa & - & $48 \mathrm{~h}$ & $600 \mathrm{mg} / \mathrm{mL}$ & $>75 \%$ & - & - & $\begin{array}{l}\text { Endocytosis } \\
\text { (Fluorescent } \\
\text { intensity) }\end{array}$ & {$[76]$} \\
\hline & $13-15$ & Cationic & $\begin{array}{l}\text { Bioorthogonal } \\
\text { probes }\end{array}$ & CHO-K1 & - & $1 \mathrm{~h}$ & $5 \mu \mathrm{M}^{\mathrm{f}}$ & - & - & $50-100$ & $\begin{array}{l}- \\
\text { (ICP-MS) }\end{array}$ & {$[77]$} \\
\hline & $\begin{array}{l}16-18 \\
(a-b)\end{array}$ & Cationic & Bioimaging & $\begin{array}{l}\text { HeLa } \\
\text { MDCK } \\
\text { (live/fixed) }\end{array}$ & $0.90-3.95$ & $48 \mathrm{~h}$ & $5 \mu \mathrm{M}^{\mathrm{f}}$ & - & - & $1-25$ & \begin{tabular}{|l|}
- \\
(Fluorescent \\
intensity)
\end{tabular} & {$[78]$} \\
\hline & 19 & Cationic & Bioimaging & $\begin{array}{l}\text { HeLa } \\
\text { KB } \\
\text { FLS }\end{array}$ & -0.12 & $48 \mathrm{~h}$ & $100 \mu \mathrm{M}$ & $>90 \%$ & - & - & \begin{tabular}{|l} 
Energy- \\
dependent \\
(ICP-AEC)
\end{tabular} & [79] \\
\hline & $20 a-g$ & Cationic & Bioimaging & $\begin{array}{l}\text { HeLa } \\
\text { LO2 }\end{array}$ & $-0.09-2.12$ & $24 \mathrm{~h}$ & $20 \mu \mathrm{M}$ & $>90 \%$ & - & - & \begin{tabular}{|l} 
Energy- \\
dependent \\
(ICP-AEC)
\end{tabular} & {$[80]$} \\
\hline 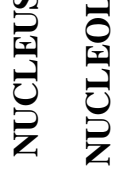 & $21-23$ & Cationic & Bioimaging & $\begin{array}{l}\text { HeLa (fixed) } \\
\text { MCF-7 } \\
\text { (fixed) }\end{array}$ & - & $24 \mathrm{~h}$ & $10-20 \mu \mathrm{M}^{\mathrm{f}}$ & - & - & $25-56$ & $\begin{array}{l}- \\
\text { (Fluorescent } \\
\text { intensity) }\end{array}$ & {$[81,82]$} \\
\hline 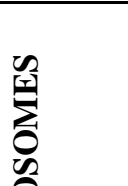 & $\begin{array}{l}24 \\
25\end{array}$ & $\begin{array}{l}\text { Neutral } \\
\text { Cationic }\end{array}$ & Bioimaging & $\mathrm{CHO}$ & - & $24 \mathrm{~h}$ & $200 \mu \mathrm{M}$ & - & - & $>200$ & $\begin{array}{l}\text { Energy- } \\
\text { dependent } \\
\text { (Flow } \\
\text { cytometry) }\end{array}$ & {$[65]$} \\
\hline 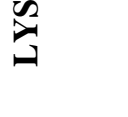 & $26 a-i$ & Neutral & Bioimaging & $4 \mathrm{~T} 1$ & $-8.12-3.18^{b}$ & $1 \mathrm{~h}$ & $0.1 \mu \mathrm{M}$ & $39-71 \%$ & - & - & $\begin{array}{l}- \\
\text { (Flow }\end{array}$ & [83] \\
\hline
\end{tabular}




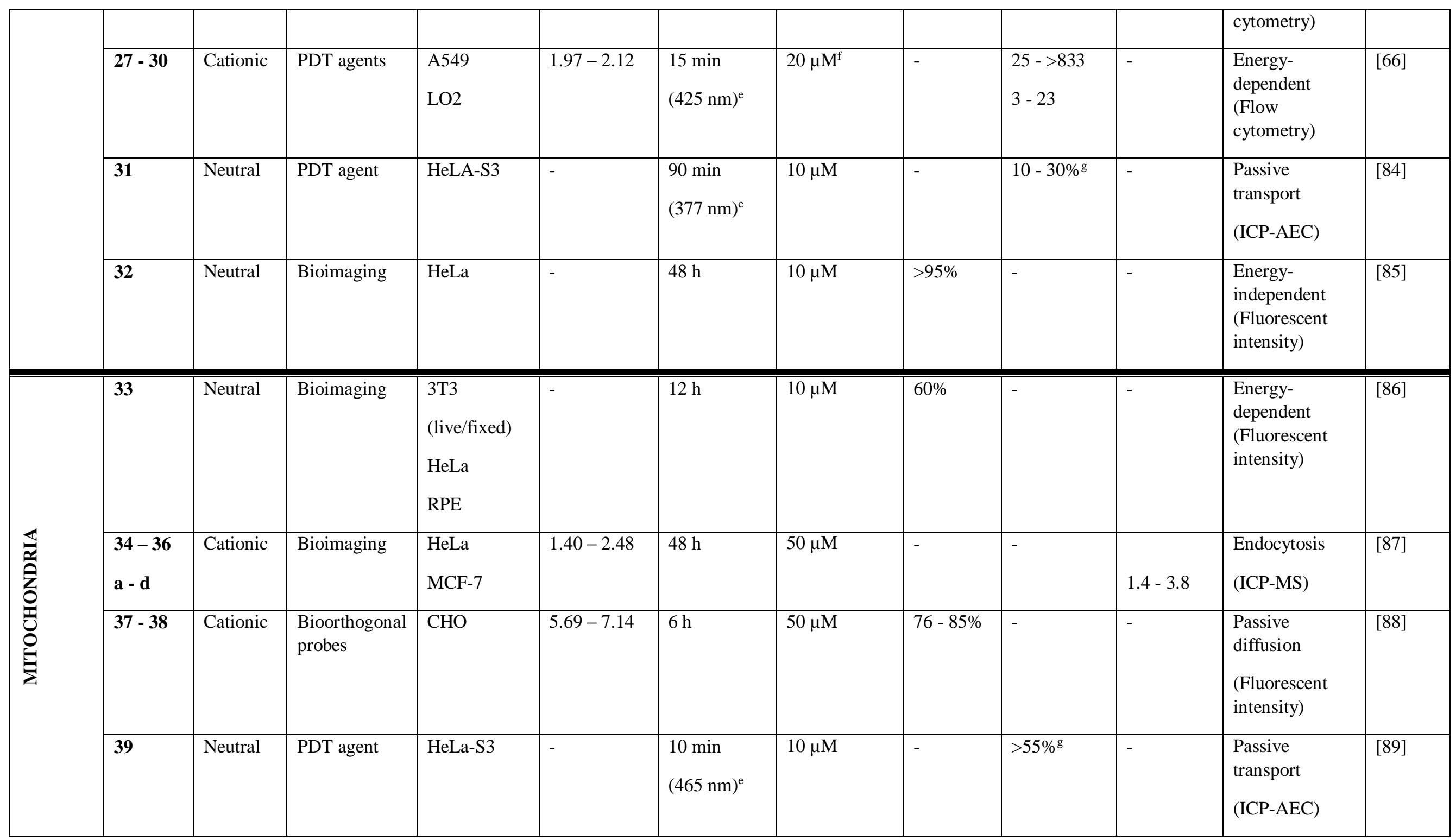




\begin{tabular}{|c|c|c|c|c|c|c|c|c|c|c|c|}
\hline $40-43$ & Cationic & $\begin{array}{l}\text { Ratiometric } \\
\text { probe }\end{array}$ & A549 & - & $12 \mathrm{~h}$ & $10 \mu \mathrm{M}$ & $>80 \%$ & - & - & $\begin{array}{l}- \\
\text { (ICP-MS) }\end{array}$ & \begin{tabular}{|l}
$90]$ \\
\end{tabular} \\
\hline $44 a-c$ & Cationic & PDT agents & $\mathrm{HeLa}$ & - & $\begin{array}{l}5 \mathrm{~min} \\
(365 \mathrm{~nm})^{\mathrm{e}}\end{array}$ & $5 \mu \mathrm{M}$ & - & $3.6-9.2$ & - & $\begin{array}{l}- \\
\text { (ICP-MS) }\end{array}$ & [91] \\
\hline $45 a-e$ & Cationic & Bioimaging & HeLa & - & $12 \mathrm{~h}$ & $0.5 \mu \mathrm{M}$ & $>85 \%$ & - & - & \begin{tabular}{|l|}
$\begin{array}{l}\text { Energy- } \\
\text { dependent }\end{array}$ \\
(ICP-MS)
\end{tabular} & [64] \\
\hline $46-48$ & Cationic & PDT agents & $\begin{array}{l}\mathrm{HeLa} \\
\mathrm{LO} 2\end{array}$ & $0.77-1.42$ & $\begin{array}{l}- \\
(405 \mathrm{~nm})^{\mathrm{e}}\end{array}$ & $0.5 \mu \mathrm{M}^{\mathrm{f}}$ & - & $\begin{array}{l}6.5-75 \\
4.5-14\end{array}$ & - & $\begin{array}{l}\text { Endocytosis } \\
\text { (ICP-MS) }\end{array}$ & [92] \\
\hline $49 a-c$ & Cationic & Bioimaging & $\mathrm{HeLa}$ & $0.9-1.5$ & $6 \mathrm{~h}$ & $5 \mu \mathrm{M}$ & - & $>80 \%^{\mathrm{g}}$ & - & \begin{tabular}{|l|}
$\begin{array}{l}\text { Energy- } \\
\text { dependent }\end{array}$ \\
(ICP-MS)
\end{tabular} & [93] \\
\hline $50-51$ & Neutral & Bioimaging & $\begin{array}{l}\text { HOS } \\
\text { (live/fixed) }\end{array}$ & - & $24 \mathrm{~h}$ & $5 \mu \mathrm{M}$ & $>80 \%$ & - & - & \begin{tabular}{|l}
- \\
(Fluorescent \\
intensity)
\end{tabular} & [94] \\
\hline $52-53$ & Cationic & $\begin{array}{l}\text { Anticancer } \\
\text { agents }\end{array}$ & $\begin{array}{l}\text { HeLa } \\
\text { A549 } \\
\text { (live/fixed) } \\
\text { MDB-MA- } \\
231 \\
\text { PC3 } \\
\text { LO2 }\end{array}$ & $0.23-2.12$ & $48 \mathrm{~h}$ & $10 \mu \mathrm{M}^{\mathrm{f}}$ & - & - & $\begin{array}{l}0.5-10 \\
0.2-24 \\
0.3-28 \\
1.0->100 \\
1.5-27\end{array}$ & $\begin{array}{l}\begin{array}{l}\text { Energy- } \\
\text { dependent }\end{array} \\
\text { (ICP-MS) }\end{array}$ & [95] \\
\hline
\end{tabular}




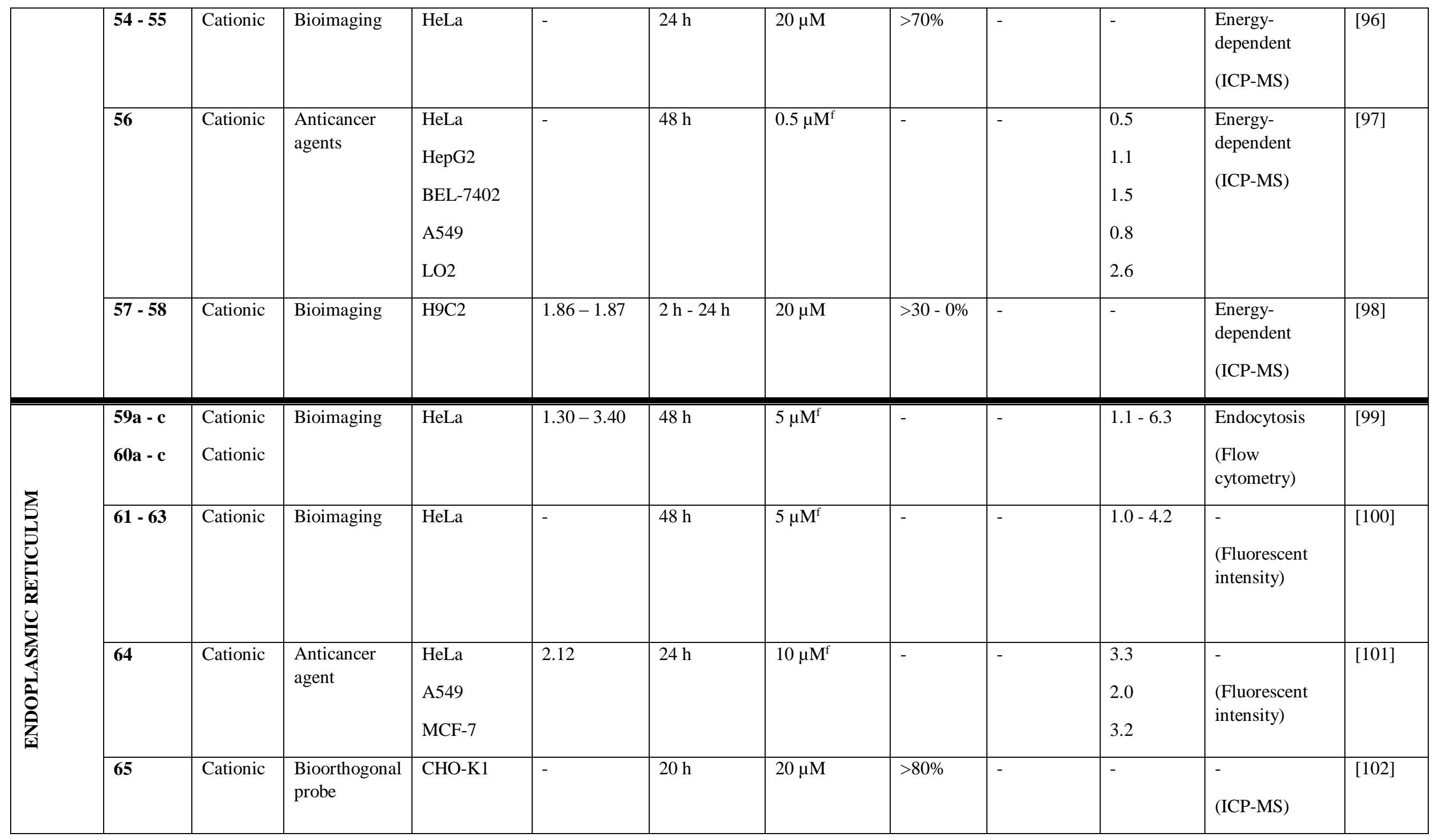




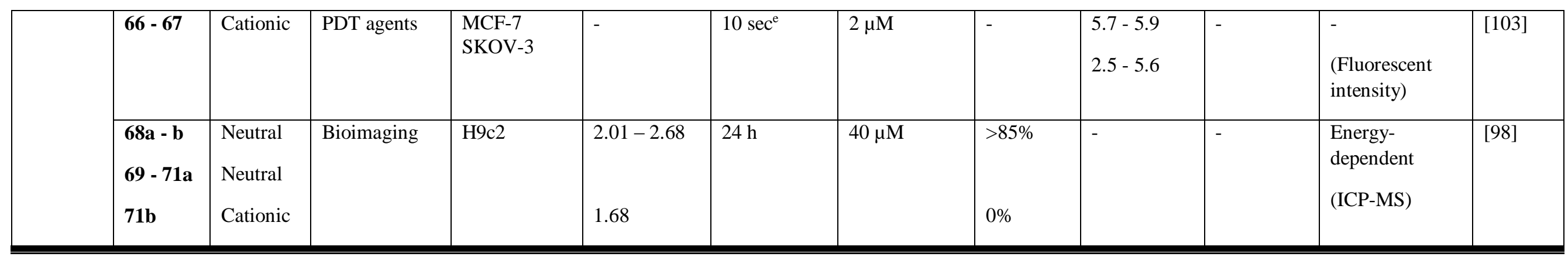

a Incubated within live cell lines, unless otherwise stated.

${ }^{b}$ Theoretically calculated copying the ChemDraw structures into the structure builder on the web site http://intro.bio.umb.edu/111-112/OLLM/111F98/newclogp.html.

${ }^{c}$ Incubation time and concentration are referred to the conditions of the cytotoxicity analysis.

${ }^{d}$ Incubation time and concentration are referred to the investigation by confocal luminescence microscopy.

e Irradiation time; in parenthesis the excitation wavelength is reported.

${ }^{f}$ Concentration is referred to the conditions of the internalisation analysis.

g Only the cytotoxicity upon exposure to light was index. 


\section{Luminescent iridium(III) probes}

\subsection{Cytoplasm staining}

The cytoplasm is the diffuse area enclosed between the cellular membrane and the nucleous. The cytoplasm hosts organelles and macromolecules, and many metabolic processes occur within this space, such glycolysis and protein folding [104]. The transport of materials between organelles also occurs in the cytoplasm, due to a process called cytoplasmic streaming $[105,106]$. The various interactions between organelles and biomolecules are highly regulated, and therefore imaging of the cytoplasm parameters and functions is a key component in life science [104].
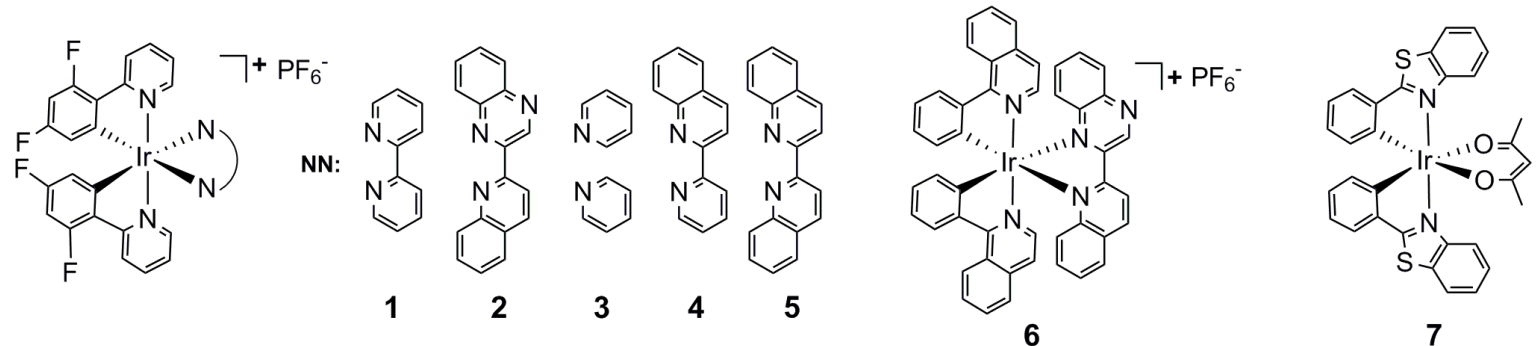

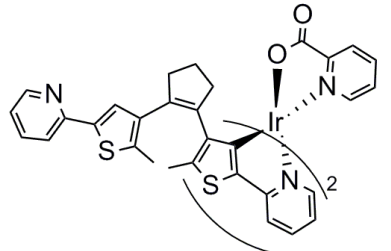

8

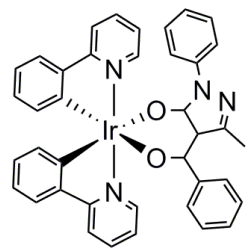

9

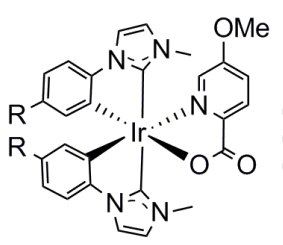

10 (a-c)

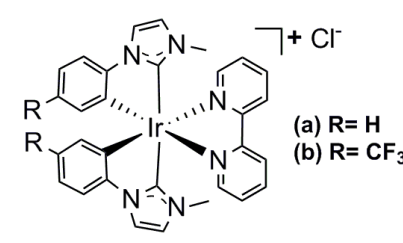

$11(a-b)$

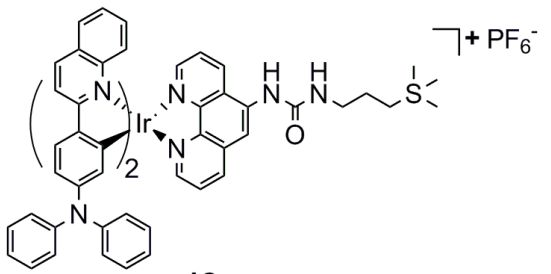

12

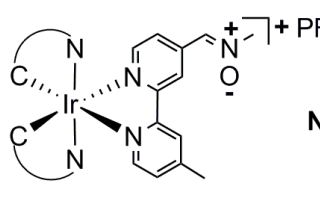

NC:

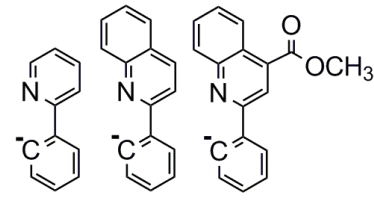

$13 \quad 14 \quad 15$

Fig. 1. Examples of iridium complexes with cytoplasmic localization. 
A library of photoactive iridium complexes displaying cytoplasmic localization is shown in Fig. 1. The majority of complexes are cationic, and only a small number of neutral iridium(III) complexes have reported showing accumulation within the cytoplasm. As a general trend, the cytotoxicity of these probes is quite low. On comparing analogous neutral and cationic complexes, the neutral complexes show lower cytotoxicity than their corresponding cationic analogues, albeit in only one illustrated study.

The first example of cyclometalated iridium(III) probes for the staining of the cytoplasm in living cells was reported by Li in 2008 [71]. Complexes 1 and 2 present the same fluorinated phenylpyridine moiety and different diamine ligands. The positive charge and the fluorination of the cyclometalated ligands, influencing the lipophilicity and aqueous solubility of the complexes, were argued to be the main factor for the internalization of these probes within the cells. Confocal images of live HeLa cells incubated with $\mathbf{1}$ and $\mathbf{2}$ in DMSO/PBS (1 : $49 \mathrm{v} / \mathrm{v})$, at a concentration of $20 \mu \mathrm{M}$ and for an incubation time of 10 minutes, show intense intracellular luminescence with high signal-to-noise ratio between the cytoplasm $\left(I_{c}\right)$ and the background $\left(I_{b}\right)$, with a ratio of $I_{c} / I_{b}$ over 50 . Moreover, the effect of the two complexes on the proliferation of MCF-7 and HCT-8 cell lines was determined by MTS assay over a period of $24 \mathrm{~h}$ incubation, showing a cellular viability greater than $90 \%$ at the highest tested concentration $(100 \mu \mathrm{M})$.

Few years later, the same group expanded on the previously presented work by preparing the cationic iridium(III) complexes [63] 3, 4, and 5, whose structures are analogous to those of $\mathbf{1}$ and $\mathbf{2}$. The group also reported complex $\mathbf{6}$, where the two cyclometalating ligands are replaced by 2-phenylisoquinoline ligands and the diimine ligand is the neutral 2-(2-quinolyl)quinoxaline) [107]. The new complexes 3-6 show similar 
biological properties in comparison to $\mathbf{1}$ and $\mathbf{2}$, albeit different photophysical behaviour, as it might be expected by the variation of the $\pi$ conjugation within the various ligands. Significant emission color tuning from blue to deep red was obtained ( $\lambda_{\max }$ from 457 to 632 $\mathrm{nm}$ ) due to the modification of the ancillary diimine ligands (3-5), which was attributed to the corresponding energy variations of the ${ }^{3} \mathrm{MLCT}\left[\mathrm{d} \pi(\mathrm{Ir}) \rightarrow \pi^{*}{ }_{\text {diimine }}\right]$ and ${ }^{3} \mathrm{LLCT}\left[\pi_{\mathrm{CN}} \rightarrow\right.$ $\pi^{*}$ diimine] excited states. An increase in the conjugation of both cyclometalated and ancillary ligands further red-shifts the emission wavelength of 6 into the near-infrared region $\left(\lambda_{\max }\right.$ $732 \mathrm{~nm}$ ) [107]. Emission in the near-infrared region is particularly appealing to biological imaging as it facilitate signal discrimination from autofluorescence, reduces scattering, and allows for deeper penetration of biological samples $[108,109]$. Like the analogous complexes 1 and 2, complexes 3-6 display predominant localization within the cytoplasm. Consistently within the small library of iridium(III) complexes, for cells incubated with complexes 3-6, the cellular viability after $24 \mathrm{~h}$ incubation time at a relatively high concentration (100 $\mu \mathrm{M})$ was again $c a .90 \%$.

Complex 7 is the first example of neutral iridium(III) complex proposed for cellular imaging, which was reported by Zhao and Li. In this complex the two cyclometalating ligands are 2-phenylbenzothiazole and the remaining ligand is the bidentate anionic O-donor acetylacetate [72]. The complex was proposed as a radiometric luminescent sensor for the quantitation of cytoplasmic $\mathrm{Hg}(\mathrm{II})$ cations. In cuvette and upon addition of 1 equivalent of $\mathrm{Hg}(\mathrm{II})$, an acetonitrile solution of complex 7 shows a blue shift of $c a .40 \mathrm{~nm}$ of $\lambda_{\max }$ that is evident in both the lowest energy absorption band and emission profile. The authors also illustrated how the shift is not affected by $\mathrm{pH}$ variations, within the range $2-12$. When incubated within live HeLa and KB cells, complex 7 shows low cytotoxicity with values of viability $\geq 90 \%$ using $100 \mu \mathrm{M}$ of $\mathbf{7}$ for $24 \mathrm{~h}$. The applicability of $\mathbf{7}$ in the ratiometric 
monitoring of intracellular $\mathrm{Hg}(\mathrm{II})$ was investigated by confocal microscopy using two optical windows: the green channel in the $515 \pm 15 \mathrm{~nm}$ range, and the yellow channel in the $570 \pm$ $10 \mathrm{~nm}$ range. $\mathrm{KB}$ cells were incubated with $10 \mu \mathrm{M}$ of the complex 7 and $10 \mu \mathrm{M}$ of $\mathrm{Hg}(\mathrm{II})$ for timeframes of 15 mins, $1 \mathrm{~h}$ and $8 \mathrm{~h}$. As it can be seen in Fig. 2, the ratio between the emission intensity at 515 and $570 \mathrm{~nm}\left(/_{515 \mathrm{~nm}} / /_{570 \mathrm{~nm}}\right)$ is negligible (ca. 0.1) when KB cells are stained with only complex 7. Upon addition of $\mathrm{Hg}(\mathrm{II}), I_{515 \mathrm{~nm}} / \mathrm{I}_{570 \mathrm{~nm}}$ increased up to 0.6 , confirming the ratiometric behaviour of complex 7 .

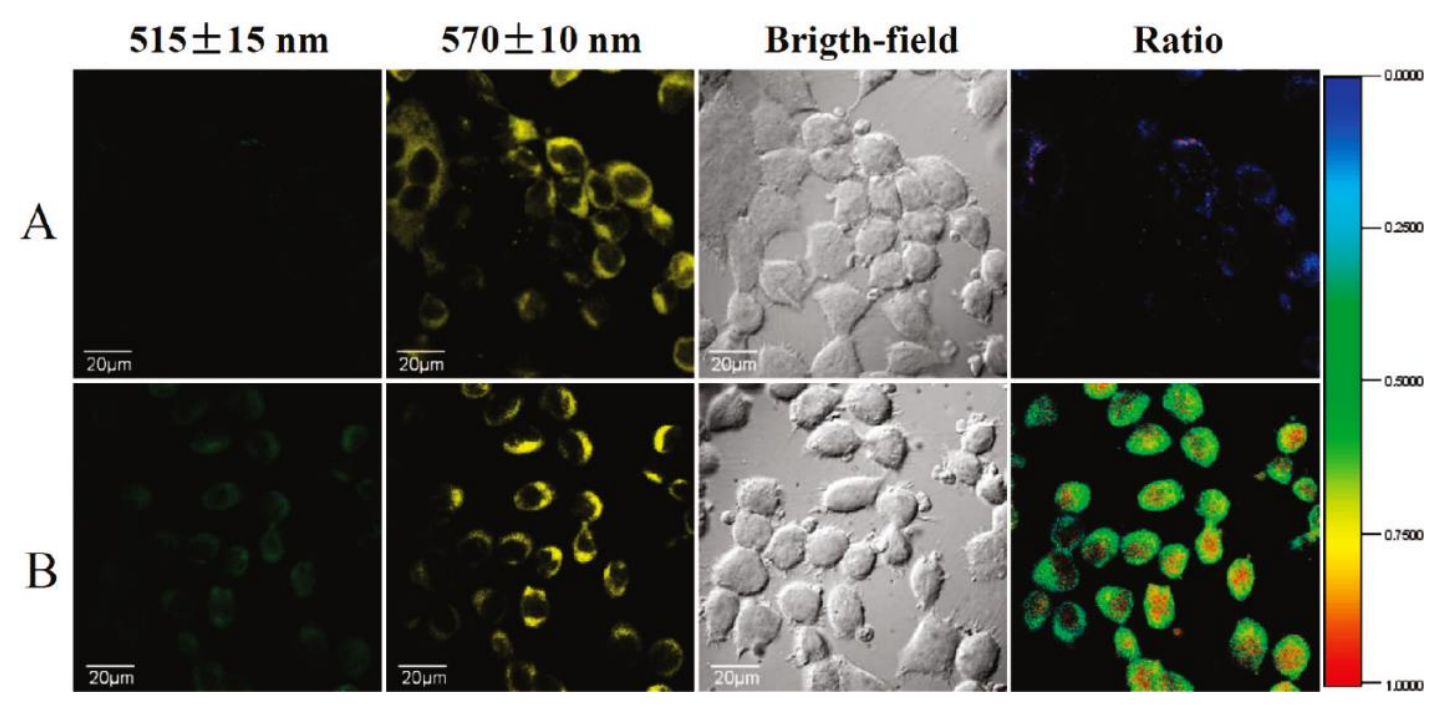

Fig. 2. Ratiometric phosphorescent images of $\mathbf{7}$ incubated in KB cells at a concentration of $10 \mu \mathrm{M}$ for $15 \mathrm{~min}$. (A) KB cells stained with 7. (B) KB cells incubated with 7 and then treated with $100 \mu \mathrm{M}$ of $\mathrm{Hg}(\mathrm{II})$ for $1 \mathrm{~h}$. Reproduced with permission from ref [72].

The neutral diarylethene-based iridium(III) complex 8 was reported by Yi and Tian [73]. The complex was designed to improve the water solubility of a previously published analogue, by replacing the acetylacetonato ligand with deprotonated 2-picolinic acid [110]. 
The MTT assay shows a cell viability greater than $80 \%$ with a concentration of $20 \mu \mathrm{M}$ and 24 $\mathrm{h}$ incubation time. By exploiting the reversible photoinduced ring opening and closing transformations of the diarylethene unit [111], the complex was proposed as a photoswitchable probe for live cells imaging triggered by visible light. Upon excitation at 488 $\mathrm{nm}$ of a diluted tetrahydrofuran solution containing complex 8 with the ligands in their open form, a yellow/orange emission with $\lambda_{\max }$ at $568 \mathrm{~nm}$ is detected. Upon continuous irradiation, the emission intensity of this band gradually decreases as the ligands undergo a photoinduced ring closing reaction, until no emission is detected. On the other hand, when the non-emissive closed form of complex $\mathbf{8}$ is continuously excited at wavelengths longer than $600 \mathrm{~nm}$, the emission band with $\lambda_{\max }$ at $568 \mathrm{~nm}$ intensity can be slowly recovered while the ligand reverses to its open form. Interestingly, a similar behaviour is detected from complex 8 when incubated within KB cells and irradiated with $458 \mathrm{~nm}$ of light for 2 minutes. The emissive open form is quenched and then recovered to the original state upon irradiation over 60 mins at $633 \mathrm{~nm}$. Unfortunately, cellular damage is detected with these photoswitching experimental conditions, limiting the exploitation of the photoswitching properties of this probe in live cells.

Zhao and Li reported the neutral $\beta$-diketonato iridium(III) complex 9, showing enhanced phosphorescent emission in the solid-state (EPESS) behaviour [74]. This complex exhibits very week luminescence $(\phi=0.04 \%)$ in diluted solution, but the gradual addition of water causes an increase of the luminescent intensity that is ascribed by the authors to aggregation. Density functional theory (DFT) calculations illustrate the existence of $\pi-\pi$ interactions involving the cyclometalated ligands, in support of the EPESS mechanism of 9. To explore the biological application of this EPESS-active complex, 9 was embedded in water-dispersible polymer nanoparticles with an average diameter of $c a .190 \mathrm{~nm}$ and 
incubated in KB cells. These embedded 9-PNPs particles internalise in only 8 minutes within the cells and exclusively stain the cytoplasm. No cytotoxicity data were reported by the authors.

Other neutral iridium(III) complexes (10a-c) were presented by Zhou [75], together with two charged biscarbene complexes (11a-b). In both neutral and cationic series, the introduction of the electron-withdrawing substituents $-\mathrm{CN}$ and $-\mathrm{CF}_{3}$ into the biscarbene ligand affects the emission maxima by inducing a hypsochromic shift in organic solvent, but an analogous clear trend was more difficult to elucidate from aqueous solutions. The authors showed that the lipophilicity value $\log P_{\mathrm{o}}$ w is mainly influenced by the overall charge of the complex for this series, and the exchange of $-\mathrm{CN}$ for $-\mathrm{CF}_{3}$ is not greatly affecting the lipophilicity. The neutral complexes 10a-c exhibit higher $\log P_{\mathrm{o} / \mathrm{w}}$ values $(1.28-1.57)$ in comparison to $11 \mathrm{a}-\mathrm{b}(0.56-0.89)$, a trend that is expected on passing from a neutral to a cationic complex. The MTT assay towards HeLa and A549 cell lines also proved the lower toxicity of neutral $10 \mathrm{a}-\mathrm{c}$ versus charged $11 \mathrm{a}-\mathbf{b}$, with average $\mathrm{IC}_{50}$ values of $c a .165 \mu \mathrm{M}$ and ca. $85 \mu \mathrm{M}$ for the neutral and charged complexes, respectively. All the complexes display cytoplasmic localization and the authors determined that cellular internalization occurred through energy-dependent uptake.

The iridium(III) complex 12 was proposed by Zhao, Li and Huang for hypoxia bioimaging [76]. Hypoxia is one of the most important feature of many diseases such as solid tumours, inflammatory diseases and cardiac ischemia [112-114]. Hence, monitoring of the oxygen level within cells is essential for the advancement of diagnostic and therapeutic techniques. The complex 12 was covalently attached to mesoporous silica-coated and lanthanide-doped core-shell nanoparticles (UCNPs@mSiO ${ }_{2}$ ). The use of a nanoparticle 
carrier for the complex 12 was proposed in order to increase aqueous solubility and stability, as well as to facilitate the use of a continuous wave near-infrared (NIR) laser at 980 $\mathrm{nm}$ with low excitation power density $\left(c a \cdot 10^{2} \mathrm{~W} \mathrm{~cm}^{-2}\right)$ [108]. The use of this excitation source was sought to minimize autofluorescence and cellular photodamage. The embedded nanoparticles 12-UCNPs@mSiO 2 cannot be efficiently excited at 980 nm within cells. Nonetheless, upon conventional excitation at $405 \mathrm{~nm}$, the probe shows responsiveness when incubated within cells with a gradient of $\mathrm{O}_{2}$. Additionally, the cytotoxicity was tested and the viability of HeLa cells result higher than $75 \%$ after $48 \mathrm{~h}$ at high concentration (600 $\mathrm{mg} / \mathrm{mL}$ ). The authors showed that 12-UCNPs@mSiO ${ }_{2}$ stains the diffuse cytoplasm and cell membrane, with uptake occurring through a nonspecific endocytotic uptake.

Three charged iridium(III)-based fluorogenic (turn-ON) bioorthogonal probes (13-15) were reported by Lo. All these complexes carry a nitrone functional group appended on the diimine ligand [77]. The nitrone unit can selectively and rapidly react with modified proteins which possess the specific alkyne reaction partner [115]. Furthermore, the incorporation of the nitrone group quenches the emission of the probe due to the photoisomerization of the $\mathrm{C}=\mathrm{N}$ bond, which provides a non-radiative deactivation pathway [116,117]. After bioconjugation with the labelled proteins (bovine serum albumin BSA, human serum albumin HAS and holo-transferrin HTf), the complexes 13-15 show a remarkable enhancement of the emission intensity $\left(I / I_{0}=92.1-795.1\right)$. The intracellular distribution of the bioconjugated complexes $\mathbf{1 3 - 1 5}$ in $\mathrm{CHO}-\mathrm{K} 1$ cell line highlights a cytoplasmic localization. Additionally, MTT assay showed that the probes are essentially non-cytotoxic toward the same cell line for an incubation period of 1 hour $\left(I C_{50}>50 \mu \mathrm{M}\right)$. 


\subsection{Nucleus \& nucleolus staining}

The nucleus is a highly specialized organelle with two main functions: storing of the cellular hereditary material in form of DNA and coordination of many processes such as growth, intermediary metabolism, protein synthesis and cell division $[118,119]$. The nucleus is bonded by a double-membrane envelope that exhibits a two-way traffic to proteins and nucleic acid between nucleus and cytoplasm [120]. The most prominent membrane-less substructure within the nucleus is the nucleolus, which is the site of rRNA transcription and processing, and also of ribosome assembly [121,122].

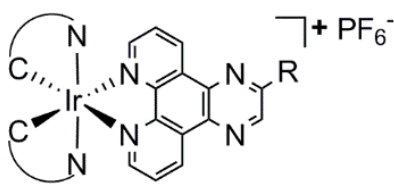

(a) $\mathrm{R}=\mathrm{H}$

(b) $\mathrm{R}=\mathrm{CONH}\left(\mathrm{CH}_{2}\right)_{3} \mathrm{CH}_{3}$
NC:

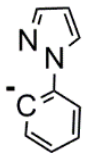

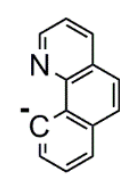

17

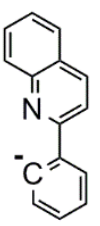

18

(a-b)

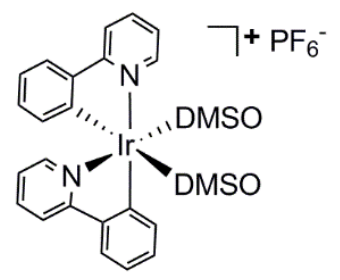

19

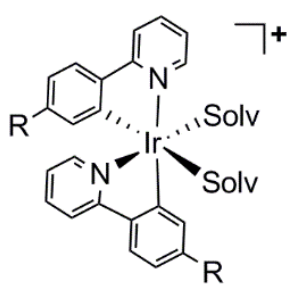

20 (a-g)
(a) $\mathrm{R}=\mathrm{H}, \mathrm{L}^{-}=\mathrm{OTf} \mathrm{O}^{-}$, Solv=DMSO
(b) $\mathrm{R}=\mathrm{H}, \mathrm{L}^{-}=\mathrm{OTf} \mathrm{T}^{\prime}$, Solv $=\mathrm{H}_{2} \mathrm{O}$
(c) $\mathrm{R}=\mathrm{H}, \mathrm{L}^{\circ}=\mathrm{OTf}^{\prime}$, Solv $=\mathrm{CH}_{3} \mathrm{CN}$
(d) $\mathrm{R}=\mathrm{Me}, \mathrm{L}^{\circ}=\mathrm{OTf}$, Solv $=\mathrm{CH}_{3} \mathrm{CN}$
(e) $\mathrm{R}=\mathrm{Et}, \mathrm{L}^{-}=\mathrm{OTf}$ ', Solv $=\mathrm{CH}_{3} \mathrm{CN}$
(f) $\mathrm{R}=i-\mathrm{Pr}, \mathrm{L}^{\circ}=\mathrm{OTf}^{-}$, Solv $=\mathrm{CH}_{3} \mathrm{CN}$
(g) $\mathrm{R}=i-\mathrm{Bu}, \mathrm{L}^{-}=\mathrm{OTf}$, Solv $=\mathrm{CH}_{3} \mathrm{CN}$

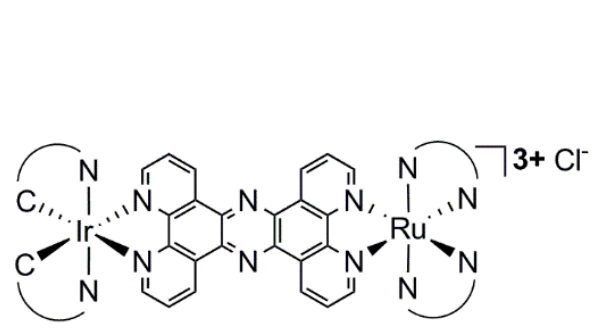

NC:<smiles>Cc1ccccc1-c1ccccn1</smiles><smiles>Cc1cc(F)cc(F)c1-c1ccccn1</smiles><smiles>Cc1cccc2ccc3cccnc3c12</smiles>

NN:<smiles>c1ccc(-c2ccccn2)nc1</smiles>

21<smiles>c1ccc(-c2ccccn2)nc1</smiles><smiles>c1cnc2c(c1)ccc1cccnc12</smiles>

22

Fig. 3. Examples of iridium complexes with nuclear localization. 
A library of iridium complexes that have been reported for the staining of the nucleus or the nucleolus is illustrated in Fig. 3. Of note, all the complexes described are cationic and there is no neutral iridium complex proposed as a nuclear stain.

One of the first examples of nucleolar staining in live cells was proposed by Lan and Lo, with a series of iridium(III) dipydoquinoxaline complexes [78]. The modification in the chemical structure of the cyclometalated ligands (16a-18a) and the presence of a long chain on the dypidoquinoxaline (16b-18b) modulate the lipophilicity and cytotoxicity of the complexes. Extending the conjugation of the ligands increases the value of $\log \mathrm{P}_{\mathrm{o} / \mathrm{w}}$ (bzq>pq>ppy) $[99,123]$ and the addition of an alkyl chain on the two phenyl rings of the cyclometalated ligand also results in an increment of the lipophilicity, especially in the case of a $n$-butyl substituent. The $\mathrm{IC}_{50}$ values of all the complexes towards HeLa and MDCK cell lines are lower than that of cisplatin, indicating high cytotoxicity, especially for the more lipophilic 17a-17b and 18a-18b. Localization studies with MDCK cell line revealed accumulation in the nucleus after 90 minutes of incubation, followed by a more specific nucleolar uptake after 120 minutes. In particular, it was proven that the complexes bind to the hydrophobic pockets of proteins and intercalate with DNA.

The group of Li developed the non-emissive iridium(III) solvato complex 19 , bound to two molecules of DMSO in place of a diimine ligand. This complex can react selectively with free histidine and histidine-rich proteins to increase its emission intensity of about 300-fold, in a fluorogenic turn-ON fashion [79]. The uptake in HeLa cell line of 19 (10 $\mu \mathrm{M}, 10$ minutes incubation time) reveal an exclusive staining of the cell nuclei, with an energy-dependent internalization pathway. Moreover, the MTT assay toward HeLa, KB and FLS cell lines 
showed low toxicity for complex $\mathbf{1 9}$, even after 48 hours, with values of viability greater than $90 \%$.

Based on the previous results, the same research group synthetized a series of nonemissive iridium(III) complexes (20a-g) by varying the counter ions, the coordinated solvent and the substituent on the phenylpyridine ligands [80]. The structure-activity relationship studies showed how the nature of the counter ions and solvent ligands do not affect the behavior of the probes within cells. On the other hand, the length of the appended carbon chain significantly influences the cellular uptake and accumulation in living cells, showing nuclei staining for the shorter chain $20 \mathrm{~d}$ and a diffused cytoplasmic accumulation for the longer 20f-g.

Thomas and Smythe proposed two heterobimetallic iridium(III)-ruthenium(II) complexes 21-22 containing a tetrapyridophenazine as a bridging ligand [81]. The probes show good water-solubility, which is often the limiting factor of many cyclometalated systems [124]. Both complexes 21 and 22 display an unstructured red emission (ca. $640 \mathrm{~nm}$ ) and low quantum yield ( $\phi<0.02 \%$ ), which increases about 10 and 24 -fold upon addition of DNA, respectively (Fig. 4). Interestingly, the binding affinity of $\mathbf{2 2}$ was lower than the nonfluorinated analogue $\mathbf{2 1}$. The lower affinity was rationalized by the increased polarity of the probe, resulting in a decrease of affinity for DNA. However, the increased lipophilicity of 22 enhances cellular uptake without loss of nuclear localization (Fig. 4). MTT assay demonstrated low cytotoxicity over a 24 hour incubation period for both $\mathbf{2 1}$ and $\mathbf{2 2}$ with $\mathrm{IC}_{50}$ values of 56 and $43 \mu \mathrm{M}$, respectively. 

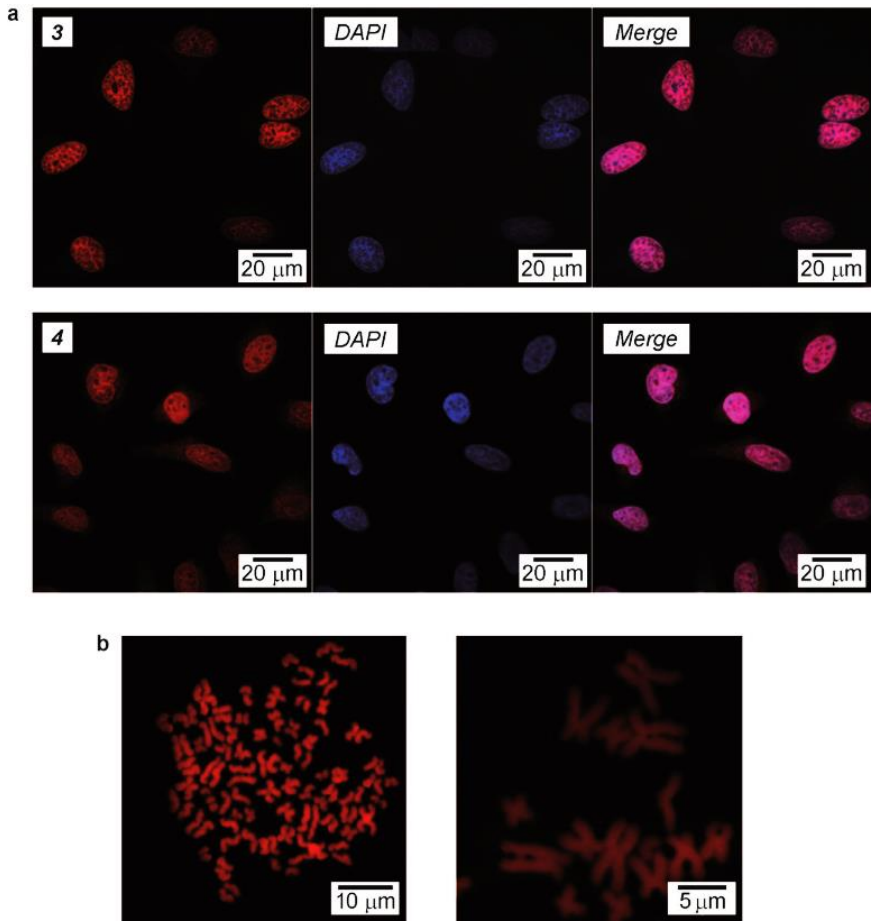

Fig. 4. a) Co-staining of 21 (3) and 22 (4) with the nuclear stain DAPI in fixed HeLa cells; b) Isolated HeLa chromosomes stained with 21 (3). Reproduced with permission from ref [81].

The same authors reported complex 23 [82] as a more lipophilic analogue of the previously discussed complexes $\mathbf{2 1}$ and $\mathbf{2 2}$. The authors could therefore compare the behavior of these probes upon a systematic increase in lipophilicity, providing evidence that increasing the lipophilic character can be counterproductive for the uptake and the specific localization of the probe. In fact, the incubation of complex 23 in MCF-7 cells $(10 \mu \mathrm{M}, 24$ hour incubation time) results in poor intracellular emission and lack of nuclear staining. Subsequent binding tests proved that complex $\mathbf{2 3}$ interacts more strongly with bovine serum albumin, which inhibits the targeted nuclear accumulation. 


\subsection{Lysosomal staining}

Lysosomes are acidic organelles containing a variety of hydrolytic enzymes capable of degrading biomacromolecules delivered by ways of phagocytosis, autophagy and endocytosis $[125,126]$. Moreover, lysosomes participate in various other cellular processes as cell migration, intracellular transport, plasma membrane repair, apoptosis and exosome release [127-129]. Lysosomal dysfunctions are associated with diverse neurodegenerative and muscular diseases, lysosomal storage disease and cancer [130-132]. For these reasons, luminescent probes for the tracking of this organelles need to possess resistance to degradation, low toxicity, high photostability, great penetration depth, near-infrared or longer excitation wavelengths and, more importantly, long-term localization $[133,134]$. 


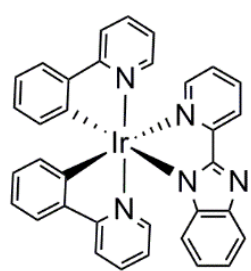

24

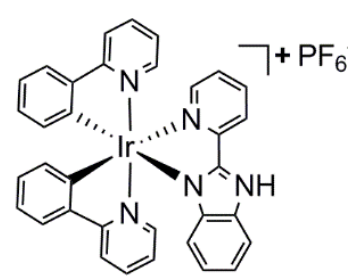

25

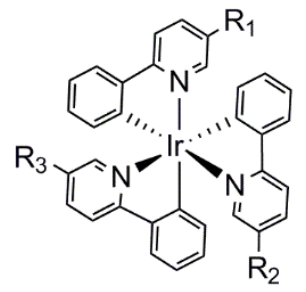

$26(a-i)$ (a) $\mathbf{R}_{\mathbf{1}}=\mathrm{CONHGlyOH}, \mathbf{R}_{\mathbf{2}}=\mathbf{R}_{\mathbf{3}}=\mathrm{H}$

(b) $\mathbf{R}_{1}=\mathbf{R}_{2}=$ CONHGlyOH, $\mathbf{R}_{2}=\mathrm{H}$

(c) $R_{1}=R_{2}=R_{3}=$ CONHGlyOH

(d) $\mathrm{R}_{1}=$ CONHAlaOH, $\mathrm{R}_{2}=\mathrm{R}_{3}=\mathrm{H}$

(e) $R_{1}=R_{2}=$ CONHAlaOH, $\mathbf{R}_{3}=\mathrm{H}$

(f) $R_{1}=R_{2}=R_{3}=$ CONHAlaOH

(g) $\mathrm{R}_{1}=$ CONHLysOMe, $\mathrm{R}_{2}=\mathrm{R}_{3}=\mathrm{H}$

(h) $\mathbf{R}_{1}=\mathbf{R}_{\mathbf{2}}=$ CONHLysOMe, $\mathbf{R}_{\mathbf{2}}=\mathrm{H}$

(i) $R_{1}=R_{2}=R_{3}=$ CONHLysOMe

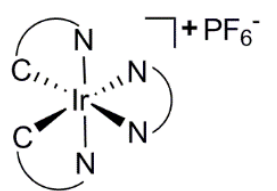<smiles></smiles><smiles>Fc1cc(F)c(-c2ccccn2)c(F)c1</smiles><smiles>Cc1ccccc1-c1ccccn1</smiles><smiles>Fc1ccc(-c2ccccn2)c(F)c1</smiles>

NN:<smiles>c1ccc2c(c1)[nH]c1c(-c3ncc[nH]3)nccc12</smiles><smiles>c1ccc2c(c1)[nH]c1c(-c3ncc[nH]3)nccc12</smiles><smiles>c1ccc2[nH]c(-c3nccc4c3[nH]c3ccccc34)nc2c1</smiles>

29

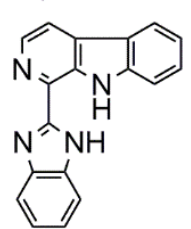

30

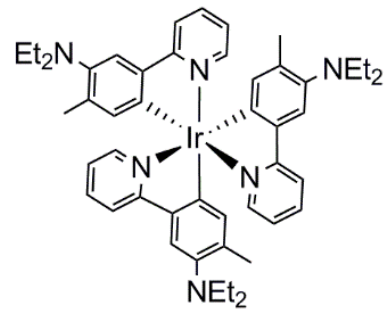

31

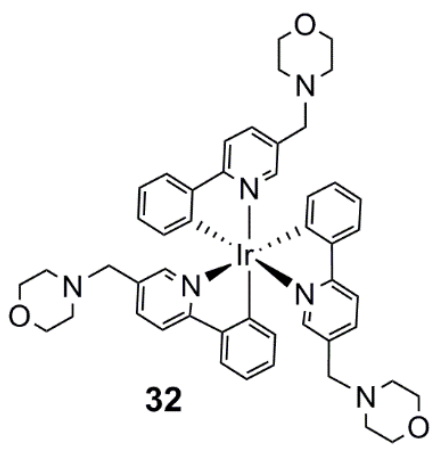

Fig. 5. Examples of iridium complexes with lysosomial localization.

Examples of iridium(III) complexes reported for the staining of lysosomes are shown in Fig. 5. While both neutral and cationic complexes have been proposed for lysosomial staining, the presence of protonable basic substituent seems to be a common factor for this family of complexes. This is not surprising given the lower $\mathrm{pH}$ of the lysosome environment.

The group of Williams published the cyclometalated iridium(III) complex 24, carrying a 2-pyridyl-benzimidazole ligand, and its protonated analogue $\mathbf{2 5}$ [65]. Photophysical data in 
dichloromethane solution shown a structured emission profile in the green region of the spectrum for 24, and an expected red shift for $\mathbf{2 5}$ with emission centered around $590 \mathrm{~nm}$. Nevertheless, the emission profiles from $\mathrm{CHO}$ cells incubated with the probes at a concentration of $10 \mu \mathrm{M}$ for 5 minutes are essentially identical. In fact, the protonation equilibrium between the two complexes is a function of the local $\mathrm{pH}$, with $\mathbf{2 4}$ being the predominant form within the cellular environments regulated at $\mathrm{pH}$ values around 7.4. A shift is observed in acidic lysosomes, as the protonation equilibrium forms the red-shifted complex 25. The MTT assay evidenced low cytotoxicity of these probes, with $\mathrm{IC}_{50}$ values > $200 \mu \mathrm{M}(200 \mu \mathrm{M}, 24$ hours incubation) for both.

A family of nine neutral iridium(III) complexes (26a-i) was synthesized by Velders. The complexes are functionalized with a different number (mono-, di-, tri-) and type (glycine, alanine, lysine) of amino acids on the 2-phenylpyridyl ligands [83]. The monosubstituted complexes $\mathbf{2 6 a}, \mathbf{2 6 d}$, and $\mathbf{2 6 g}$ show a remarkable $\mathbf{2 0}$-fold higher cellular uptake in $4 \mathrm{~T} 1$ cells (10 $\mu \mathrm{M}, 1$ hour incubation), a trend that was associated with the more lipophilic nature of the probes [135]. This result was supported by the authors with the determination of the theoretical lipophilicity $(\operatorname{Cog} P)$, which shows a distribution coefficient between 2.05 and 3.18 , in comparison to the negative values of $C \log P$ for the di- $(\mathbf{2 6 b}, \mathbf{2 6 e}$ and $26 \mathrm{~h})$ and trisubstituted (26c, $\mathbf{2 6 f}$ and $\mathbf{2 6 i )}$ complexes. Analysis by flow cytometry showed a substantial reduction of the cell viability for the lysine-derivatives (26a-c), with higher toxicity for the more substituted complex 26c with viability lower than $39 \%$. The cellular distribution of complexes 26a-c displays different localization, depending of the number of lysine residues, with nuclear staining for mono-26a, endosomes staining for bis-26b and lysosome staining for tris-26c. 
Four iridium(III) complexes with $\beta$-carboline ligands (27-30) were developed by Tan and Mao as $\mathrm{pH}$-responsive tumour/lysosome-targeted photodynamic therapeutic (PDT) agents [66]. The pH-response can be achieved with the introduction of the protonation sites on the imidazole and benzimidazole groups $[136,137]$. On the other hand, the selectivity toward acidic environment can be enhanced by the presence of the $\beta$-carboline ligand [138]. The complexes show similar lipophilicity values $(1.97-2.12)$, with a greater cell penetration for the smaller imidazole-derivatives 27-28. Upon irradiation, they show highly selective phototoxicity against A549 cancer cells. In particular, complex 28 displays a phototoxicity index of greater than 833. Even if all the complexes localize within the lysosome, $\mathbf{2 8}$ is the more promising to be used to track the lysosomal integrity during PDT, which provides a convenient method for in situ monitoring of therapeutic effects.

The group of Aoki developed a neutral iridium(III) probe $\mathbf{3 1}$ that can be used as luminescent $\mathrm{pH}$-sensor and also a pH-dependent photosensitizer in live cells [84]. Photophysical analysis in degassed DMSO/100 $\mu \mathrm{M}$ aqueous buffer have shown a blue shifted emission maximum upon addition of 1 equivalent of acid, and an enhancement of the emission intensity induced by the second and third protonation of the diethylamino groups. As predicted, through a passive transport mechanism, complex $\mathbf{3 1}$ localizes within the lysosomes of HeLa-S3 cells. Additionally, photoirradiation of $\mathbf{3 1}$ at 377 and $470 \mathrm{~nm}$ for 30 minutes induces necrosis-like death in HeLa-S3 cells, demonstrating the ability of the probe to generate ${ }^{1} \mathrm{O}_{2}$ in a $\mathrm{pH}$-dependant manner.

An interesting neutral iridium(III) probe for a long-term lysosomes tracking was designed by Chao [85]. The water-soluble triscyclometalated iridum(III) complex is functionalized by morpholine moieties, which can be protonated inside the lysosome [139] 
and work as a "locker", allowing the accumulation of $\mathbf{3 2}$ in these acidic organelles (Fig. 6). Additionally, the electron-rich morpholine quenches the iridium(III) phosphorescence by photoinduced electron transfer (PET) in basic condition, but upon protonation this process is suppressed, leading to an enhancement of the emission intensity in acidic lysosomes. The uptake of complex 32 occurs through an energy-dependent pathway and the probe results nontoxic for HeLa cell lines (10 $\mathrm{MM}, 48$ hour incubation). Moreover, 32 is able to track lysosomes for a period of 4 days, allowing imaging and observation of most physiological activities of the lysosomes.

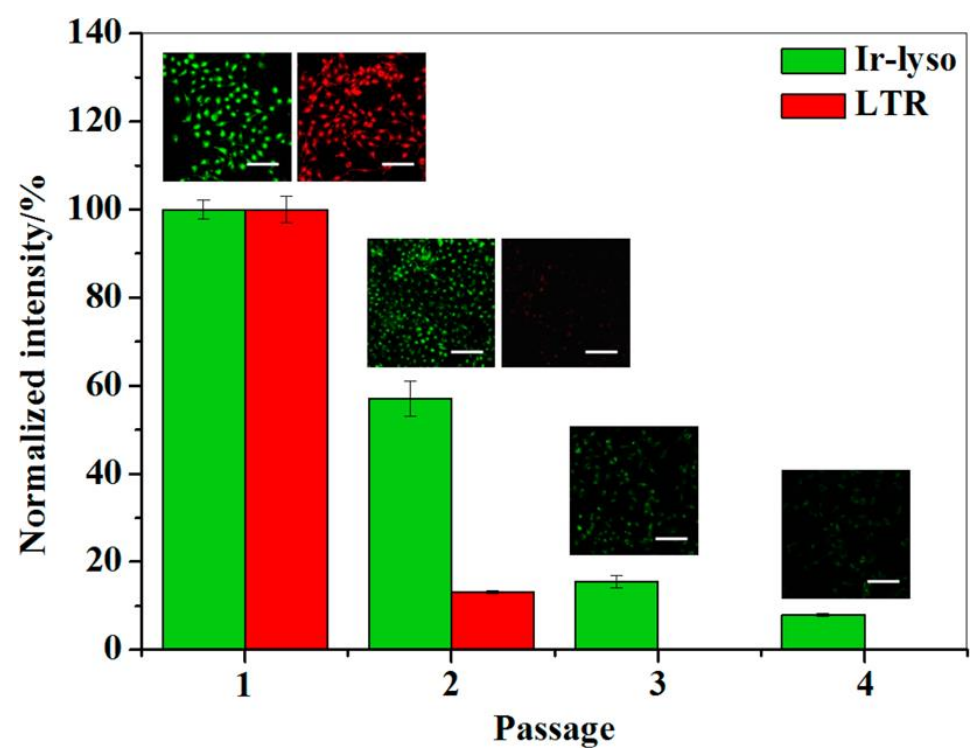

Fig. 6. Normalized emission intensities and images of living HeLa cells stained with $2 \mu \mathrm{M}$ of complex 32 (Ir-lyso) and $2 \mu \mathrm{M}$ of LysoTracker Red DND-99 (LTR) at different passages. Scale bar: $100 \mu \mathrm{m}$. Reproduced with permission from ref [85]. 


\subsection{Mitochondrial staining}

Mitochondria are rod-shaped organelles performing diverse functions, involving energy production via oxidative phosphorylation, calcium modulation, redox signalling, and apoptosis [140,141]. Furthermore, mitochondria are dynamic organelles that frequently change their number, size, shape and distribution within the cytoplasm in response to metabolic and environmental stress [142]. It is therefore not surprising that mitochondrial dysfunction has emerged as a key factor in a range of diseases, including metabolic disorders, cancer and neurodegenerative diseases, such as Alzheimer and Parkinson [143].

Fig. 7 illustrates various iridium(III) complexes reported to localize within the mitochondria. The majority of the complexes are positively charged, with very limited examples of neutral species developed for the staining of mitochondria. In general, the requirement of a positive charge is associated to a facilitation of mitochondrial localization through the membrane electrical potential.

A charged iridium(III) complex carrying a phenanthroline ligand and functionalized with a isothiocyanate group (33) was developed to target specific mitochondrial proteins [86]. As a previous study showed [100], the isothiocyanate unit allows the probe to covalently bind to amine-containing biomolecules such as lysine and the $\mathrm{N}$-terminal of proteins, yielding luminescent bioconjugates. Interestingly, complex $\mathbf{3 3}$ accumulates only in the mitochondria of living 3T3, HeLa and RPE cells, while a diffuse staining is present with prefixed $3 T 3$ cells, indicating that the process requires active cellular metabolism. The binding of complex $\mathbf{3 3}$ to mitochondrial proteins interferes with the function and the morphology of this organelle, as showed in the MTT assay. The viability of 3T3 cells decreases to $60 \%$ with concentration higher than $10 \mu \mathrm{M}$ and an incubation time of 12 hours. 
Another series of bioconjugated iridium(III) complexes was proposed by Lo [87]. In this case, the complexes are appended with a $\beta$-D-glucose (34a-d) or a D-galactose unit (35a-d) via a polyethylene glycol linker to the diimine ligand, while the degree of $\pi$ conjugation was varied on the cyclometalated ligands. The general idea is to increase the specific cellular uptake of these sugar-appended probes in cancer cells, which usually show an elevated expression of glucose transporters (GLUTs) and hexokinase to support their higher metabolic functions [144,145]. The lipophilicity was tested highlighting the main contributing factor was the nature of the cyclometaled ligands(a, c, d $>>\mathbf{b})$. In fact, the complexes of the groups $\mathbf{3 4}$ and $\mathbf{3 5}$ show similar values of lipophilicity when the cyclometalated ligand is the same. Overall, the lipophilicities of $\mathbf{3 4}(\mathbf{a}-\mathbf{d})$ and $\mathbf{3 5}(\mathrm{a}-\mathrm{d})$ are slightly lower than 36, illustrating the effect of the polar carbohydrate groups. Additionally, the cytotoxicity toward HeLa cells $\left(50 \mu \mathrm{M}, 48\right.$ hours) displays lower $\mathrm{IC}_{50}$ values in comparison to cisplatin for almost all the probes. Both $\mathbf{3 4 a}$ and 35 a localize within mitochondria through an energy-dependent pathway, but only complex 34a enters the cells using a GLUT-mediated mechanism. 


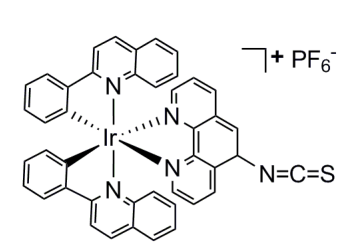

33

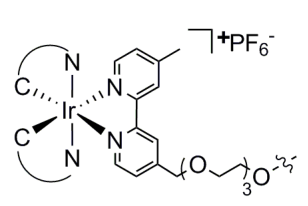

NC:

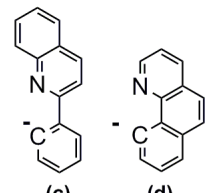

$$
{ }_{34 \text { (a-d) }}
$$
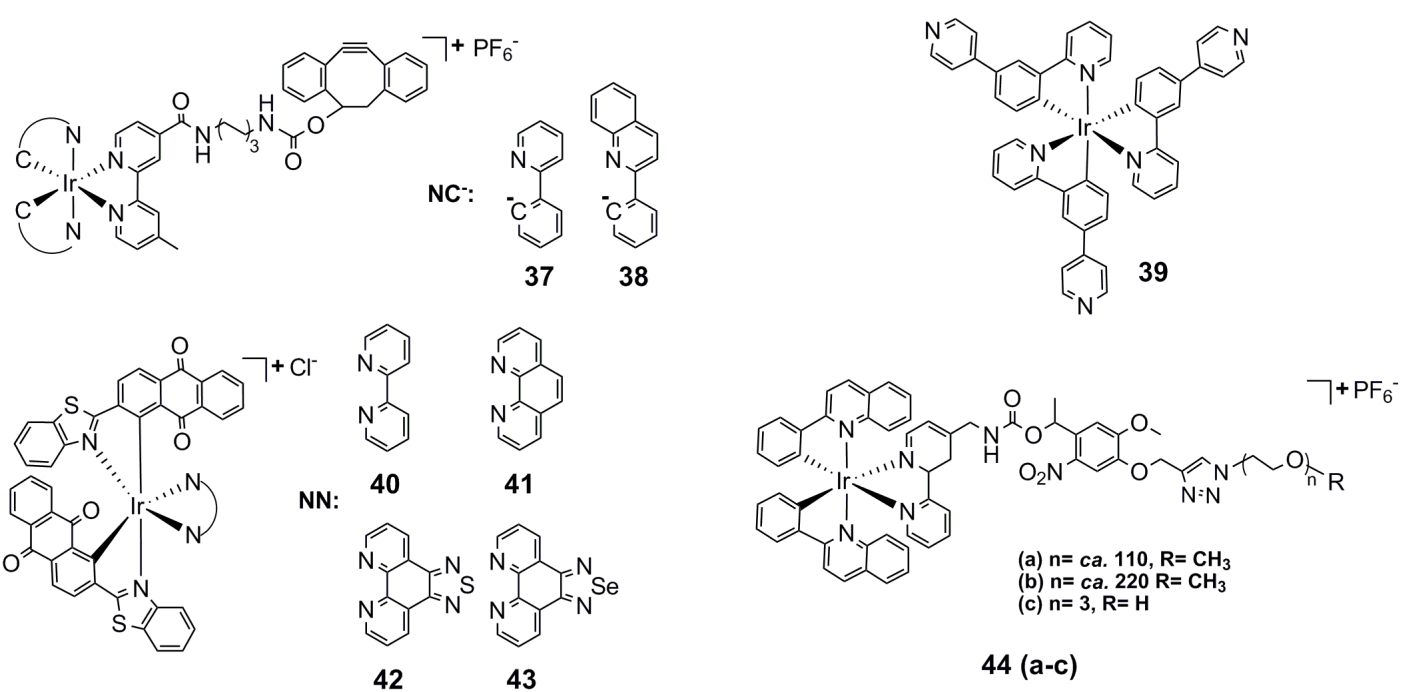

$44(\mathrm{a}-\mathrm{c})$

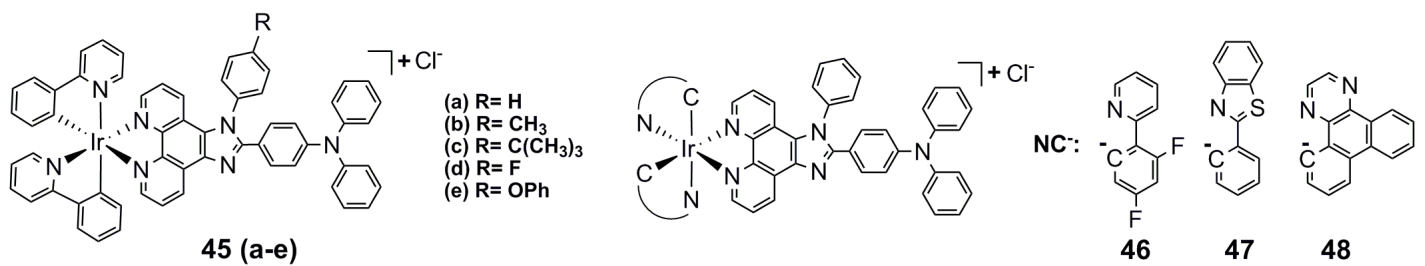

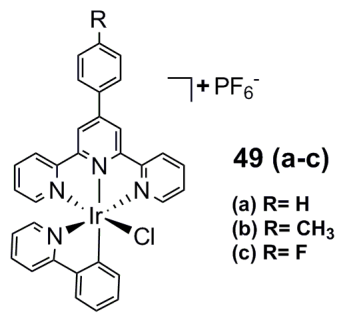

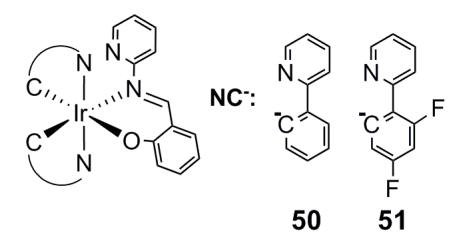

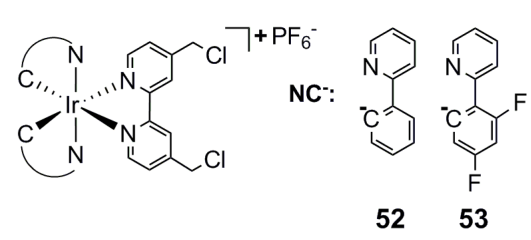

$52 \quad 53$

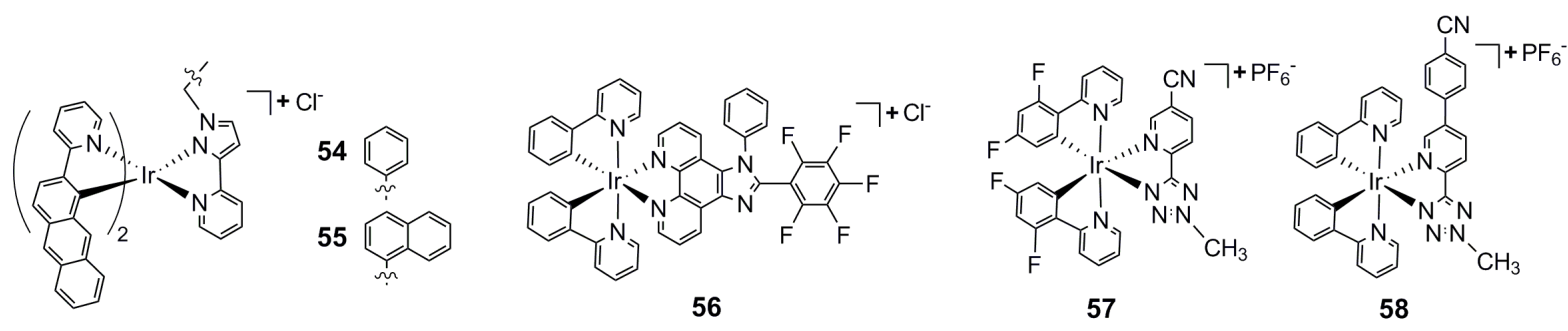

Fig. 7. Examples of iridium(III) complexes displaying localization within the mitochondria. 
Two charged bioorthogonal iridium(III) probes (37-38) were reported by Lo. The complexes are appended with a dibenzocyclooctyne moiety [88], which is capable of targeting different azide-labelled biomolecules [146]. Lipophilicity studies of $\mathbf{3 7}$ and $\mathbf{3 8}$ revealed very high values of 5.69 and 7.14, respectively. Both complexes exhibit mitochondrial localization in $\mathrm{CHO}$ cells achieved through a passive diffusion. Regardless of the higher lipophilicity of $\mathbf{3 8}$, complex $\mathbf{3 7}$ enters the cells more efficiently, suggesting that the smaller molecular size plays a critical role in the uptake of the probe. Both complexes exhibit a moderate cytotoxicity with a percentage of surviving $\mathrm{CHO}$ cell of $75.6 \%$ and $84.9 \%$, at a concentration of $50 \mu \mathrm{M}$ for an incubation time of 6 hours.

After their previous publication on $\mathrm{pH}$-responsive probes [84], the group of Aoki synthesized a further neutral iridium(III) analogue containing three pyridyl groups at the 4'position of the phenylpyridine ligand (39) [89]. Complex 39 exhibits a reversible pHdependent emission profile based on protonation and deprotonation on the pyridine rings, with a green intense emission in neutral and basic condition and a weaker red emission in acidic $\mathrm{pH}$. Upon incubation in HeLa-S3 cells, complex 39 accumulates within mitochondria, potentially through a passive transport mechanism. Moreover, after photoirradiation at 465 $\mathrm{nm}$ for 10 minutes, 39 generates much more ${ }^{1} \mathrm{O}_{2}$ in comparison to the previous published iridium(III) probe [84], thus inducing necrosis-like cell death. 


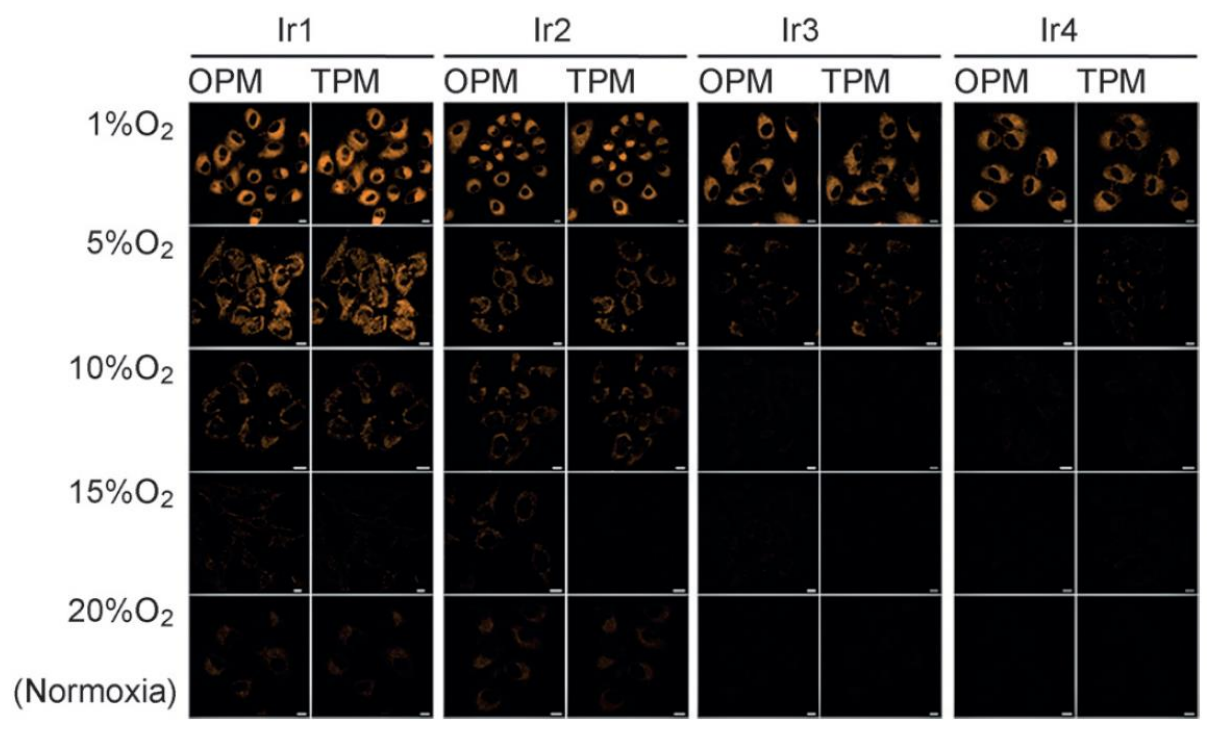

Fig. 8. Confocal images of adherent A549 cells treated with $5 \mu \mathrm{M}$ of complexes $\mathbf{4 0 - 4 3}$ (Ir1Ir4) under normoxic $\left(20 \% \mathrm{O}_{2}\right)$ and different hypoxic $\left(15,10,5\right.$ and $\left.1 \% \mathrm{O}_{2}\right)$ conditions. Scale bar: $10 \mu \mathrm{m}$. Reproduced with permission from ref [90].

The group of Chao developed four iridium(III) anthraquinone complexes (40-43) that can be excited via two-photon absorption, as hypoxia-sensitive imaging probes [90]. The anthraquinone unit is an efficient quencher of the iridium luminescence. However, in hypoxic conditions, it can be converted into the hydroquinone form, thus restoring the emission of the probe [147]. In cells, the ligand can be reduced by the coenzyme nicotinamide adenine reductase phosphate $(\mathrm{NAD}(\mathrm{P}) \mathrm{H})$ in the presence of cellular reductase [148]. Interestingly as shown in Fig. 8, the emission intensity of the complexes 40-43 internalized within A549 cells rapidly increases (11- to 19-fold) after enzymatic reactions with $\mathrm{NAD}(\mathrm{P}) \mathrm{H}$ in hypoxic condition, without interference from other biological reductants. Moreover, the probes display different sensitivity toward oxygen, with an increment of phosphorescence at $\left[\mathrm{O}_{2}\right] \leq 5 \%$ for $\mathbf{4 0}$, and $1 \%$ or less for $\mathbf{4 1 - 4 3}$. All the probes localize in the 
mitochondria of A549 cells and show quite low cytotoxicity with viability values greather than $80 \%$ under both normoxic and hypoxic conditions, after 12 hours incubation at a concentration of $10 \mu \mathrm{M}$.

A series of photoactivatable iridium(III) (44a-c) complexes functionalized with a nitroveratryl photolabile protecting group and polyethylene glycol chains of various lengths were designed by Lo [91]. The polyethylene glycol chain increases water solubility [149], and also reduces the toxicity as the chain increases in length. In fact, despite similar uptake efficiency within this small family of complexes, the viability in the dark of HeLa cells incubated with $44 a$ and $44 b(>80 \%)$ is higher than for $44 c(>60 \%)$, due to the greater biocompatibility of the longer polyethylene glycol chain. Upon irradiation for 5 minutes, the nitroveratryl group is cleaved and the cytotoxic iridium(III) core is released, showing a significant decrease of the percentage of cell survival. The complexes $44 a-b$ display good accumulation within the mitochondria.

The group of Chao synthesized five iridium(III) complexes (45a-e) [64] with aggregation-induced emission (AIE) characteristics, showing almost no fluorescence in solution and high emission in the aggregated state [150]. All the complexes exhibit low toxicity (viability $>85 \%$ ), upon incubation at $500 \mathrm{nM}$ for a period of 12 hours. The uptake in the mitochondria of HeLa cells follows a non-endocytic energy dependent process. Remarkably, 45a was employed to successfully monitor a mitophagy [151] process in living cells.

The same research group recently published a similar series of AlE-active iridium(III) probes (46-48), which are analogous to the family of complexes 45 with variations in the cyclometalated ligands. In line with the previously reported complexes, these species can 
also be used as a two-photon absorbing agents for photodynamic therapy (PDT) [92]. In particular, the complex 46 displays a significant two-photon absorption cross-section, a really high ROS (reactive oxygen species) generation capacity and an impressive lethality at low concentration upon aggregation within mitochondria.

Another family of terpyridyl iridium(III) complexes (49a-c) for the real-time dynamic tracking of mitophagy [151] with two-photon excitation was proposed by Chao [93]. These probes exhibit lipophilicity values $\log \mathrm{D}_{7.4}$ in a range between 0.9 and 1.5 and moderate cytotoxicity in HeLa cells, with a viability greater than $80 \%$ after 6 hour incubation at a concentration of $5 \mu \mathrm{M}$. Interestingly, the complexes $49 \mathrm{a}-\mathrm{c}$ are capable of localizing within the mitochondria independently of the membrane potential, an advantageous characteristic over the commercially available mitochondrial stain MitoTracker Red (which in the absence of membrane potential distributes within the cytoplasm and other organelles). Moreover, 49a-c show deep tissue penetration under two-photon excitation, enabling the visualisation of the inner structure of tridimensional multicellular tumour spheroids [152].

Laskar and Chowdhury designed two of the few examples of neutral iridium(III) probes (50-51) for the staining of mitochondria [94]. As Chao's probes [64,92], 50 and 51 exhibit aggregation induced emission with an increment of the emission intensity in the solid state 60 and 34 times higher than in solution, respectively. Additionally, these complexes show a low toxicity at concentration lower than $5 \mu \mathrm{M}$ (viability $>80 \%$ ) for an incubation time of 24 hours in HOS cells and specific mitochondrial staining.

Mao and Tan synthesized two chloromethyl functionalized iridium(III) complexes (52-53) with differently functionalized bipyridine as diimine ligands [95]. These complexes are designed to react with thiol functional groups present in various mitochondrial proteins 
and immobilize the complexes inside this organelle [153]. The cytotoxicity of $\mathbf{5 2 - 5 3}$ was tested against a series of cancer cell lines, showing very low $I C_{50}$ values $(0.2-27 \mu \mathrm{M})$ after 48 hour treatment. Additionally, $\mathbf{5 2}$ shows a 11-fold higher selectivity for cancerous A459 cells over noncancerous LO2 cells, inducing a caspase-dependent and ROS-mediated apoptotic cell death [154].

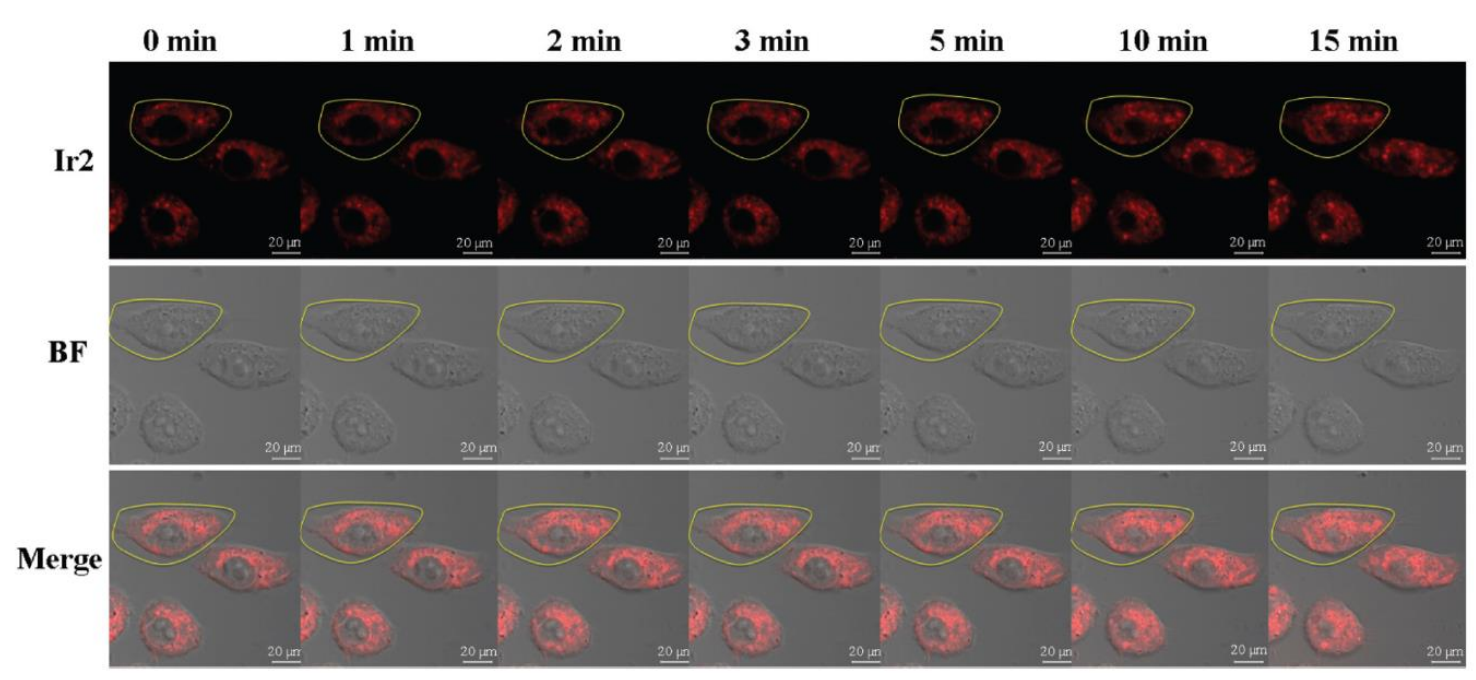

Fig. 9. Phosphorescent images of CCCP (carbonyl cyanide m-chlorophenyl hydrazone) (10 $\mu \mathrm{M})$ treated living HeLa cells stained with $20 \mu \mathrm{M}$ of $55(\operatorname{Ir} 2)$ and an increasing scan time. The upper panels are the luminescence images of $\operatorname{Ir2}(\mathbf{5 5})$, the middle panels are the bright-field (BF) images, whereas the lower panels are the merged images. Reproduced with permission from ref [96].

The complexes $\mathbf{5 4}$ and $\mathbf{5 5}$ are some of the few examples of NIR iridium(III) probes [96], due to the presence of phenylbenzo[g]quinoline as cyclometalated ligands [109]. These complexes display a strong emission band around ca. $750 \mathrm{~nm}$, superior photostability and reduced $\mathrm{pH}$ dependence of the phosphorescent intensity. Those properties, in addition to a 
low cytotoxicity with viability greater than $70 \%$ after 24 hour of incubation at $20 \mu \mathrm{M}$ in HeLa cells, have allowed to track the changing in the mitochondrial morphology during the early stage of apoptosis (Fig. 9).

Based on the structure of previously reported iridium(III) derivatives $[64,155]$, the group of Chao synthesized a family of complexes to assess the effect of various degrees of fluorination on anti-proliferation [97]. In particular, the complex with the highest degree of fluorination (56) shows high cytotoxicity against 5 different human cancer cell lines $\left(\mathrm{IC}_{50}\right.$ values: $0.5-2.6 \mu \mathrm{M}$ ) with also the highest selectivity to the cisplatin-resistant cell line A549R.

Our research group developed two charged iridium(III) tetrazolato complexes, functionalized with a cyano unit (57-58) [98]. Both complexes localize within the mitochondria in live cardiomyoblast H9c2 cells. Interestingly, complex $\mathbf{5 7}$ is also found within the endoplasmic reticulum, whereas complex $\mathbf{5 8}$ almost exclusively accumulate within the mitochondria. These two complexes display similar value of lipophilicity (1.86 and 1.87 for $\mathbf{5 7}$ and $\mathbf{5 8}$, respectively) and similar incubation within cells as revealed by ICP-MS [98]. These complexes are characterized by high cytotoxicity when incubated at $20 \mu \mathrm{M}$ for 24 hours. 


\subsection{Endoplasmic reticulum staining}

The endoplasmic reticulum (ER) is the largest membrane-bound organelle in eukaryotic cells and it consists of multiple structural domain that are interconnected and contiguous [156]. The ER serves different roles within the cell such as protein folding, lipid and steroid synthesis, carbohydrate metabolism and calcium storage and release [157]. Importantly, a number of physiological and pathological conditions are known to disturb proper ER function and thereby cause ER stress, which can lead to unfolded protein response (UPR) or the release of calcium in the cytoplasm, followed by mitochondria mediated apoptosis $[158,159]$. 
$\overbrace{\mathrm{C}}^{\mathrm{C}} \mathrm{NC}$

(a)

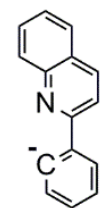

(b)

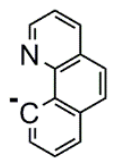

(c)
NN:

59 (a-c)

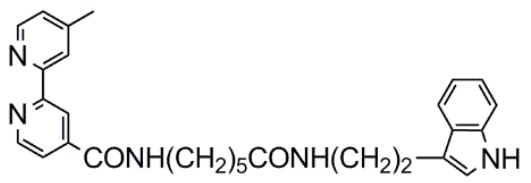

60 (a-c)

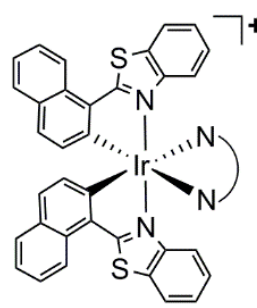

NN:

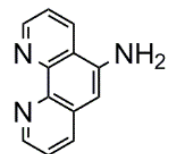

61

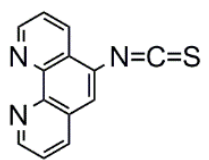

62

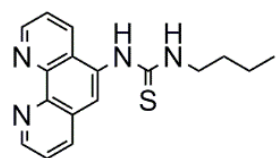

63

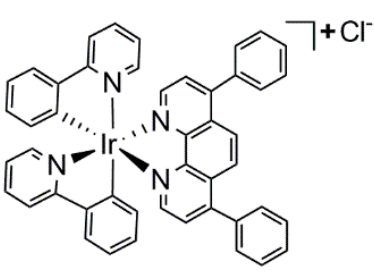

64

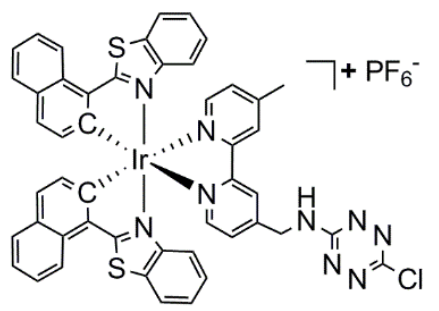

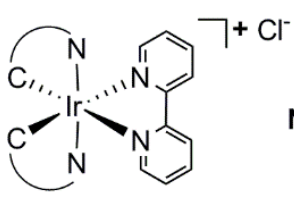

NC:<smiles>Cc1ccccc1-c1ccnc2c(-c3ccccc3C)cccc12</smiles>

$66 \quad 67$

65

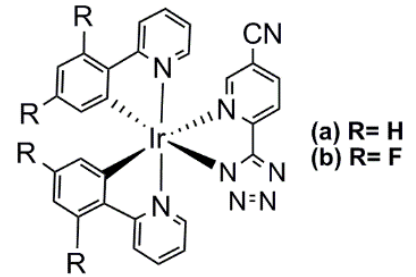

68 (a-b)

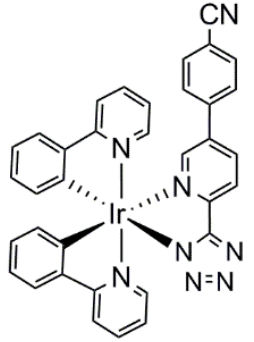

69

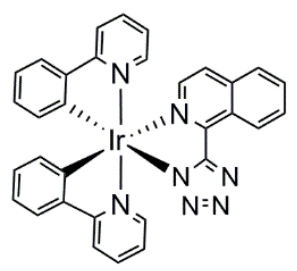

70

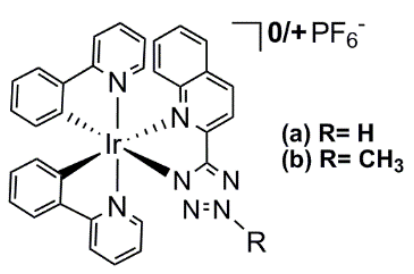

71 (a-b)

Fig. 10. Iridium complexes proposed for the staining of the endoplasmic reticulum.

A family of iridium(III) complexes that display localization within the endoplasmic reticulum is shown in Fig. 10. A look over these complexes highlights that the majority of them are cationic and exhibit acute cytotoxicity. On the other hand, neutral complexes with 
accumulation within the endoplasmic reticulum appear to exhibit lower cytotoxicity, even at longer incubation time.

One of the first examples of ER probes was a series of charged iridium(III) complexes appended with an indole moiety (59a-c/60a-c) [99]. In fact, the binding properties of the indole unit with proteins such as serum albumin, which contains six specific substratebinding sites $[160,161]$ are well known. Lipophilicity measurements shown slightly higher values for the probes with a longer spacer (60a-c), compared with their analogues (59a-c), and increased $\log \mathrm{D}_{7.4}$ along with the higher conjugation of the two cyclometalating ligands (c>b >a). Additionally, all the probes display high levels of cytotoxicity toward HeLa cell, with $\mathrm{IC}_{50}$ values ranged from 1.1 to $6.3 \mu \mathrm{M}$ at 48 hour incubation time. Through an energyrequiring process such as endocytosis, 60a localized in the perinuclear area of cells.

A family of three iridium(III) complexes bound to functionalized 1,10-phenanthroline ligands (61-63) was studied by the group of Lo [100]. The complex 63 was the only probe in the series that can undergo bioconjugation with proteins, such as bovine serum albumin or human serum albumin. Surprisingly, the intracellular distribution of 61-63 in HeLa cells was the same, with the formation of a luminescent ring surrounding the nucleus. Additionally, cytotoxicity data have shown similar $I_{50}$ values $(1.0-4.2 \mu \mathrm{M})$, revealing the high toxicity of these probes.

The bathophenanthroline iridium(III) probe 64 was discovered by Fei and Zhou [162]. The size and the conjugation degree of the diimine ligand increases the lipophilicity and cytotoxicity of complex 63 in comparison with a previous published analogue [163]. The greater lipophilicity causes the localization of the probes in the membrane of the endoplasmic reticulum, causing ER stress and initiating an intrinsic apoptotic pathway 
$[158,159]$. Additionally, the high cytotoxicity against HeLa, A549 and MCF-7 cell lines has highlighted the antitumor potential of 64 , with $\mathrm{IC}_{50}$ values of $3.3,2.0$ and $3.2 \mu \mathrm{M}$, respectively.

The bioorthogonal iridium(III) complex 65 containing a 1,2,4,5-tetrazine moiety is almost non-emissive, but its emission highly enhances upon selective coordination with modified bovine serum albumin $\left(I / I_{0}=1113.7\right)$ [102]. The cytotoxicity of the probe was tested by MTT assay on $\mathrm{CHO}-\mathrm{K} 1$ cells and shows a viability greater than $80 \%$ after 20 hour incubation at concentration up to $20 \mu \mathrm{M}$. The localization of complex 65 shows a perinuclear and sharp granular cytoplasmic staining, due to the dynamic recycling of the probe from the endoplasmic reticulum to subcellular organelles for enzymatic processing [164].

Kwon, Rhee and Lim reported two bipyridine iridium(III) complexes (66-67) which can be used as PDT (photodynamic therapy) agents, due to their high efficiency in the production of ROS [103]. In fact, at really low concentration $(2 \mu \mathrm{M})$ the probes can be photoactivated (10 second irradiation time, $100 \mathrm{~J} \mathrm{~cm}^{-2}$ light) and reduce significantly the cell viability of SKOV-3 cancer cells, with $\mathrm{IC}_{50}$ values of $4.89 / 0.83 \mu \mathrm{M}(66)$ and 3.61/0.63 $\mu \mathrm{M}(67)$ in the absence/presence of light. Interestingly, the localization of the probes was mainly in the endoplasmic reticulum, but the ${ }^{1} \mathrm{O}_{2}$ produced might be diffused through the ER membrane and also modify some mitochondrial proteins, by protein-protein cross-linking and protein oxidation mechanisms.

Our research group developed a series of neutral iridium(III) tetrazolato probes (68ab, 69, 70, 71a), which predominantly stain ER of H9c2 cells (Fig. 11) [98]. Noteworthy, the MTS assay has showed low cytotoxicity at $40 \mu \mathrm{M}$ and $24 \mathrm{~h}$ incubation time, with a cell viability greater than $85 \%$, and an active transport mechanism for the internalization of 
these probes. Interestingly, the probes localized also within lipid droplets, as seen for the complexes $\mathbf{7 0}$ and $\mathbf{7 1 a}$ in Fig. 11, to various degrees, which is not very commonly observed for cyclometalated iridium(III) complexes $[165,166]$. The charged $\mathbf{7 1 b}$ exhibits the same stain pattern than the neutral compounds, but it shows high toxicity toward H9c2 cells.

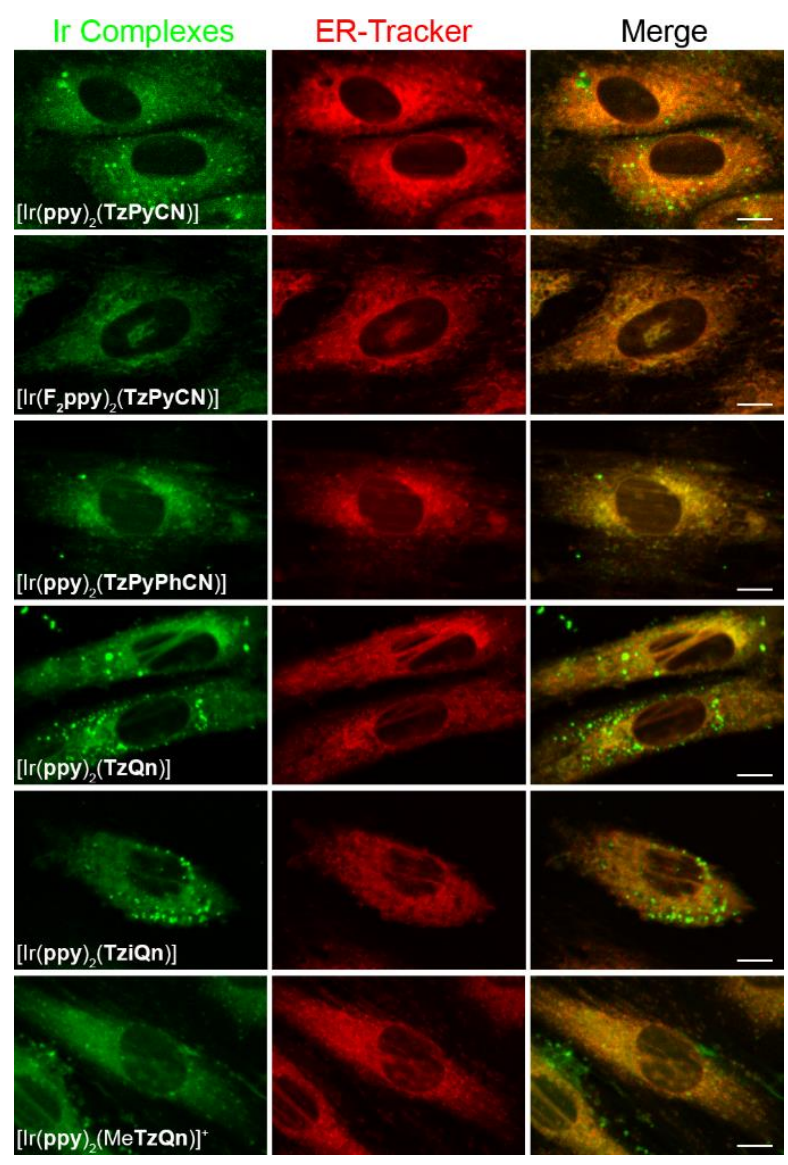

Fig. 11. Iridium complexes (from the top 68-71b) interacting with endoplasmic reticulum in live H9c2 cells. Micrographs of H9c2 cells stained with the iridium complexes (green) and ER Tracker (red). Scale bar: $10 \mu \mathrm{m}$. Reproduced with permission from ref [98].

\section{Outlook and conclusions}

This review surveyed the research area of cyclometalated iridium(III) complexes and their use in life science. It is evident that this area is still incredibly active and it has been 
diversified over the years. While phosphorescent iridium(III) complexes were initially screened as cellular markers for optical imaging, their versatility has expended potential use in broader areas including therapy. Despite the large body of work that has appeared in the literature to date, a full rationalization of structure-activity relationship is still difficult to achieve. Most of the design of new iridium probes and/or therapeutic agents starts with considerations of chemical nature such as charge, lipophilicity, solubility and bioconjugation to specific biological vectors. However, as illustrated in the various examples within this review, a systematic investigation related to a biological context is lacking. In fact, the various research groups have been tested the iridium complexes in very different conditions including diverse cell lines, concentration and incubation time. The area, in its multidisciplinary feature bridging chemistry and biology, would certainly benefit for the establishment of a set of conditions to assess newly synthesized iridium(III) complexes and to revise currently available ones. Nevertheless, it is very evident that the future research involving the use of cyclometalated iridium complexes in life science is certainly active and bright.

\section{Conflict of Interest}

The iridium complexes $\mathbf{5 7}, \mathbf{5 8}, \mathbf{6 8 - 7 1}$ are commercially available through ReZolve Scientific; MM is a shareholder of ReZolve Scientific.

\section{Acknowledgments}

MM wishes to thank for Australian Research Council for funding (FT130100033). CC wishes to thanks Curtin University for a CSIRS Scholarship. 


\section{References}

[1] R.A. Benson, I.B. McInnes, J.M. Brewer, P. Garside, Nat. Rev. Rheumatol. 11 (2015) 111.

[2] P. Lang, K. Yeow, A. Nichols, A. Scheer, Nat. Rev. Drug Discov. 5 (2006) 343-356.

[3] R.S. Negrin, C.H. Contag, Nat. Rev. Immunol. 6 (2006) 484-490.

[4] D. Toomre, J. Bewersdorf, Annu. Rev. Cell Dev. Biol. 26 (2010) 285-314.

[5] T. Hirayama, K. Okuda, H. Nagasawa, Chem. Sci. 4 (2013) 1250-1256.

[6] S.C. Dodani, S.C. Leary, P.A. Cobine, D.R. Winge, C.J. Chang, J. Am. Chem. Soc. 133 (2011) 8606-8616.

[7] D.-L. Ma, S. Lin, W. Wang, C. Yang, C.-H. Leung, Chem. Sci. 8 (2017) 878-889.

[8] K. Qiu, Y. Chen, T.W. Rees, L. Ji, H. Chao, Coord. Chem. Rev. (2017).

[9] K.K.-W. Lo, A.W.-T. Choi, W.H.-T. Law, Dalt. Trans. 41 (2012) 6021-6047.

[10] L.E. Wedlock, S.J. Berners-Price, Aust. J. Chem. 64 (2011) 692-704.

[11] E. Baggaley, J. a. Weinstein, J. a G. Williams, Coord. Chem. Rev. 256 (2012) 17621785.

[12] A. Sorvina, C.A. Bader, M.C. Lock, D.A. Brooks, J.L. Morrison, S.E. Plush, J. Biophotonics (2017) 1-8.

[13] C. Stringari, J. Biomed. Opt. 17 (2012) 1-11.

[14] C. Ma, K. Wu, H. Liu, K. Xia, K. Wang, J. Wang, Anal. Methods 8 (2016) 7453-7459.

[15] Y. Wang, C. Song, M. Wang, Y. Xie, L. Mi, G. Wang, IEEE J. Sel. Top. Quantum Electron. $22(2016) 1-7$. 
[16] P. Schulze, D. Belder, Anal. Bioanal. Chem. 393 (2009) 515-525.

[17] Q. Li, S. Seeger, Appl. Spectrosc. Rev. 45 (2010) 12-43.

[18] D. Aigner, S.M. Borisov, F.J. Orriach Fernández, J.F. Fernández Sánchez, R. Saf, I. Klimant, Talanta 99 (2012) 194-201.

[19] L. Long, X. Li, D. Zhang, S. Meng, J. Zhang, X. Sun, C. Zhang, L. Zhou, L. Wang, RSC Adv. 3 (2013) 12204-12209.

[20] N. Panchuk-Voloshina, R.P. Haugland, J. Bishop-Stewart, M.K. Bhalgat, P.J. Millard, F. Mao, W.Y. Leung, R.P. Haugland, J. Histochem. Cytochem. 47 (1999) 1179-1188.

[21] X.-F. Zhang, T. Zhang, S.-L. Shen, J.-Y. Miao, B.-X. Zhao, J. Mater. Chem. B 3 (2015) $3260-3266$.

[22] H. Zhu, J. Fan, J. Du, X. Peng, Acc. Chem. Res. 49 (2016) 2115-2126.

[23] H.N. Kim, M.H. Lee, H.J. Kim, J.S. Kim, J. Yoon, Chem. Soc. Rev. 37 (2008) 1465-1472.

[24] L.D. Lavis, R.T. Raines, ACS Chem. Biol. 3 (2008) 142-155.

[25] J. Liu, Y.Q. Sun, H. Zhang, H. Shi, Y. Shi, W. Guo, ACS Appl. Mater. Interfaces 8 (2016) $22953-22962$.

[26] K.P. Quinn, G. V. Sridharan, R.S. Hayden, D.L. Kaplan, K. Lee, I. Georgakoudi, Sci. Rep. $3(2013) 1-10$.

[27] M.C. Skala, K.M. Riching, A. Gendron-Fitzpatrick, J. Eickhoff, K.W. Eliceiri, J.G. White, N. Ramanujam, Proc. Natl. Acad. Sci. 104 (2007) 19494-19499.

[28] T.S. Blacker, Z.F. Mann, J.E. Gale, M. Ziegler, A.J. Bain, G. Szabadkai, M.R. Duchen, Nat. Commun. 5 (2014) 1-9.

[29] C.W. Shuttleworth, Neurochem Int. 56 (2011) 379-386. 
[30] A. Ghisaidoobe, S. Chung, Int. J. Mol. Sci. 15 (2014) 22518-22538.

[31] N. Tayeh, T. Rungassamy, J.R. Albani, J. Pharm. Biomed. Anal. 50 (2009) 107-116.

[32] J. leee, O.F. April, N. Electronics, IEEE J. Quantum Electron. (1971) 178-179.

[33] A.D. Britt, W.B. Moniz, IEEE J. Quantum Electron. 5 (1972) 307-309.

[34] C. Eggeling, J. Widengren, R. Rigler, C.A.M. Seidel, Anal. Chem. 70 (1998) 2651-2659.

[35] M.P. Coogan, V. Fernandez-Moreira, Chem. Commun. 50 (2013) 384-99.

[36] Hua-Wei Liu, K.Y. Zhang, W.H.T. Law, K.K.W. Lo, Organometallics 29 (2010) 34743476.

[37] M. Mauro, A. Aliprandi, D. Septiadi, N.S. Kehr, L. De Cola, Chem. Soc. Rev. 43 (2014) 4144-4166.

[38] E.J. New, D. Parker, D.G. Smith, J.W. Walton, Curr. Opin. Chem. Biol. 14 (2010) 238246.

[39] J.-C.G. Bünzli, Interface Focus 3 (2013) 1-17.

[40] N. Sim, D. Parker, Chem. Soc. Rev. 44 (2015) 2122-2134.

[41] X. Wang, H. Chang, J. Xie, B. Zhao, B. Liu, S. Xu, W. Pei, N. Ren, L. Huang, W. Huang, Coord. Chem. Rev. 273-274 (2014) 201-212.

[42] D.G. Smith, B.K. McMahon, R. Pal, D. Parker, Chem. Commun. 48 (2012) 8520-8522.

[43] K.K.W. Lo, Acc. Chem. Res. 48 (2015) 2985-2995.

[44] L. Flamigni, A. Barbieri, C. Sabatini, B. Ventura, F. Barigelletti, Top Curr Chem 281 (2007) 45-100.

[45] V. Balzani, A. Credi, M. Venturi, Top Curr Chem 171 (2007) 143-203. 
[46] P. Hanninen, H. Harma, Lanthanide Luminescence, Photophysical, Analytical and Biological Aspects, 2011.

[47] J.-C.G. Bünzli, S. V. Eliseeva, Photophysics of Lanthanoid Coordination Compounds, 2013.

[48] J.-C.G. Bünzli, C. Piguet, Chem. Soc. Rev. 34 (2005) 1048-1077.

[49] J.C.G. Bünzli, Chem. Rev. 110 (2010) 2729-2755.

[50] V. Fernandez-Moreira, F.L. Thorp-Greenwood, M.P. Coogan, Chem. Commun. (Camb). 46 (2010) 186-202.

[51] F.L. Thorp-Greenwood, R.G. Balasingham, M.P. Coogan, J. Organomet. Chem. 714 (2012) 12-21.

[52] S.W. Botchway, M. Charnley, J.W. Haycock, A.W. Parker, D.L. Rochester, J.A. Weinstein, J.A.G. Williams, Proc. Natl. Acad. Sci. 105 (2008) 16071-16076.

[53] E. Baggaley, S.W. Botchway, J.W. Haycock, H. Morris, I. V. Sazanovich, J.A.G. Williams, J.A. Weinstein, Chem. Sci. 5 (2014) 879-886.

[54] M.W. Louie, H.W. Liu, M.H.C. Lam, Y.W. Lam, K.K.W. Lo, Chem. - A Eur. J. 17 (2011) 8304-8308.

[55] U. Jungwirth, C.R. Kowol, B.K. Keppler, G. Christian, Antioxid Redox Signal 15 (2011) $1085-1127$.

[56] T. Mcmahon, P.C.M. Van Zijl, A.A. Gilad, Photochem. Photobiol. 90 (2014) 257-274.

[57] P.R. Ogilby, Chem. Soc. Rev. 39 (2010) 3181-3209.

[58] R.E. Doherty, I. V. Sazanovich, L.K. McKenzie, A.S. Stasheuski, R. Coyle, E. Baggaley, S. Bottomley, J.A. Weinstein, H.E. Bryant, Sci. Rep. 6 (2016) 1-9. 
[59] A. Kastl, S. Dieckmann, K. Wähler, T. Völker, L. Kastl, A.L. Merkel, A. Vultur, B. Shannan, K. Harms, M. Ocker, W.J. Parak, M. Herlyn, E. Meggers, ChemMedChem 8 (2013) 924-927.

[60] L.K. McKenzie, I. V. Sazanovich, E. Baggaley, M. Bonneau, V. Guerchais, J.A.G. Williams, J.A. Weinstein, H.E. Bryant, Chem. - A Eur. J. 23 (2017) 234-238.

[61] B.S. Howerton, D.K. Heidary, E.C. Glazer, J. Am. Chem. Soc. 134 (2012) 8324-8327.

[62] J. Liu, C. Jin, B. Yuan, Y. Chen, X. Liu, L. Ji, H. Chao, Chem. Commun. 53 (2017) 98789881.

[63] Q. Zhao, M. Yu, L. Shi, S. Liu, C. Li, M. Shi, Z. Zhou, C. Huang, F. Li, Organometallics 29 (2010) 1085-1091.

[64] C. Jin, J. Liu, Y. Chen, R. Guan, C. Ouyang, Y. Zhu, L. Ji, H. Chao, Nat. Publ. Gr. (2016) 113.

[65] L. Murphy, A. Congreve, L.-O. Pålsson, J. a G. Williams, Chem. Commun. (Camb). 46 (2010) 8743-8745.

[66] L. He, Y. Li, C.-P. Tan, R.-R. Ye, M.-H. Chen, J.-J. Cao, L.-N. Ji, Z.-W. Mao, Chem. Sci. 6 (2015) 5409-5418.

[67] T.F. Anjong, G. Kim, H.Y. Jang, J. Yoon, J. Kim, New J. Chem. 41 (2017) 377-386.

[68] K.K.-S. Tso, K.K.-W. Lo, Iridium(III) Optoelectron. Photonics Appl. (2017) 415-477.

[69] A. Baschieri, S. Muzzioli, V. Fiorini, E. Matteucci, M. Massi, L. Sambri, S. Stagni, Organometallics 33 (2014) 6154-6164.

[70] D. Parker, Aust. J. Chem. 64 (2011) 239-243.

[71] M. Yu, Q. Zhao, L. Shi, F. Li, Z. Zhou, H. Yang, T. Yi, C. Huang, Chem. Commun. (2008) 
$2115-2117$.

[72] Y. Wu, H. Jing, Z. Dong, Q. Zhao, H. Wu, F. Li, Inorg. Chem. 50 (2011) 7412-7420.

[73] W. Tan, J. Zhou, F. Li, T. Yi, H. Tian, Chem. - An Asian J. 6 (2011) 1263-1268.

[74] H. Wu, T. Yang, Q. Zhao, J. Zhou, C. Li, F. Li, Dalt. Trans. 40 (2011) 1969-1976.

[75] Y. Zhou, J. Jia, W. Li, H. Fei, M. Zhou, Chem Commun 49 (2013) 3230-3232.

[76] W. Lv, T. Yang, Q. Yu, Q. Zhao, K.Y. Zhang, H. Liang, S. Liu, F. Li, W. Huang, Adv. Sci. 2 (2015) 1-9.

[77] L.C.C. Lee, J.C.W. Lau, H.W. Liu, K.K.W. Lo, Angew. Chemie - Int. Ed. 55 (2016) 10461049.

[78] K.Y. Zhang, S.P.Y. Li, N. Zhu, L.W.S. Or, M.S.H. Cheung, Y.W. Lam, K.K.W. Lo, Inorg. Chem. 49 (2010) 2530-2540.

[79] C. Li, M. Yu, Y. Sun, Y. Wu, C. Huang, F. Li, J. Am. Chem. Soc. 133 (2011) 11231-11239.

[80] C. Li, Y. Liu, Y. Wu, Y. Sun, F. Li, Biomaterials 34 (2013) 1223-1234.

[81] A. Wragg, M.R. Gill, D. Turton, H. Adams, T.M. Roseveare, C. Smythe, X. Su, J. a. Thomas, Chem. - A Eur. J. 20 (2014) 14004-14011.

[82] A. Wragg, M.R. Gill, L. McKenzie, C. Glover, R. Mowll, J. a. Weinstein, X. Su, C. Smythe, J. a. Thomas, Chem. - A Eur. J. 21 (2015) 11865-11871.

[83] P. Steunenberg, A. Ruggi, N.S. Van Den Berg, T. Buckle, J. Kuil, F.W.B. Van Leeuwen, A.H. Velders, Inorg. Chem. 51 (2012) 2105-2114.

[84] S. Moromizato, Y. Hisamatsu, T. Suzuki, Y. Matsuo, R. Abe, S. Aoki, Inorg. Chem. 51 (2012) 12697-12706. 
[85] K. Qiu, H. Huang, B. Liu, Y. Liu, Z. Huang, Y. Chen, L. Ji, H. Chao, ACS Appl. Mater. Interfaces 8 (2016) 12702-12710.

[86] B. Wang, Y. Liang, H. Dong, T. Tan, B. Zhan, J. Cheng, K.K.W. Lo, Y.W. Lam, S.H. Cheng, ChemBioChem 13 (2012) 2729-2737.

[87] W.H.T. Law, L.C.C. Lee, M.W. Louie, H.W. Liu, T.W.H. Ang, K.K.W. Lo, Inorg. Chem. 52 (2013) 13029-13041.

[88] K.K.-W. Lo, B.T.-N. Chan, H.-W. Liu, K.Y. Zhang, S.P.-Y. Li, T.S.-M. Tang, Chem. Commun. 49 (2013) 4271-4273.

[89] A. Nakagawa, Y. Hisamatsu, S. Moromizato, M. Kohno, S. Aoki, Inorg. Chem. 53 (2014) 409-422.

[90] L. Sun, Y. Chen, S. Kuang, G. Li, R. Guan, J. Liu, L. Ji, H. Chao, Chem. - A Eur. J. 22 (2016) 8955-8965.

[91] K.K.-S. Tso, K.-K. Leung, H.-W. Liu, K.K.-W. Lo, Chem. Commun. 52 (2016) 4557-4560.

[92] J. Liu, C. Jin, B. Yuan, X. Liu, Y. Chen, L. Ji, H. Chao, Chem. Commun. 53 (2017) 20522055.

[93] H. Huang, P. Zhang, K. Qiu, J. Huang, Y. Chen, L. Ji, H. Chao, Sci. Rep. 6 (2016) 1-12.

[94] P. Alam, S. Dash, C. Climent, G. Kaur, A.R. Choudhury, D. Casanova, P. Alemany, R. Chowdhury, I.R. Laskar, RSC Adv. 7 (2017) 5642-5648.

[95] J.-J. Cao, C. Tan, M.-H. Chen, N. Wu, D.-Y. Yao, X. Liu, L.-N. Ji, Z.-W. Mao, Chem. Sci. 8 (2017) 631-640.

[96] Y. Liu, P. Zhang, X. Fang, G. Wu, S. Chen, Z. Zhang, H. Chao, W. Tan, L. Xu, Dalt. Trans. 46 (2017) 4777-4785. 
[97] M. Ouyang, L. Zeng, H. Huang, C. Jin, J. Liu, Y. Chen, L. Ji, H. Chao, Dalt. Trans. 46 (2017) 6734-6744.

[98] C. Caporale, C.A. Bader, A. Sorvina, K.D.M. MaGee, B.W. Skelton, T.A. Gillam, P.J. Wright, P. Raiteri, S. Stagni, J.L. Morrison, S.E. Plush, D.A. Brooks, M. Massi, Chem. - A Eur. J. 23 (2017) 15666-15679.

[99] J.S.Y. Lau, P.K. Lee, K.H.K. Tsang, C.H.C. Ng, Y.W. Lam, S.H. Cheng, K.K.W. Lo, Inorg. Chem. 48 (2009) 708-718.

[100] K.K.W. Lo, S.K. Leung, C.Y. Pan, Inorganica Chim. Acta 380 (2012) 343-349.

[101] R. Cao, J. Jia, X. Ma, M. Zhou, H. Fei, J. Med. Chem. 56 (2013) 3636-3644.

[102] S.P.-Y. Li, A.M.-H. Yip, H.-W. Liu, K.K.-W. Lo, Biomaterials 103 (2016) 305-313.

[103] J.S. Nam, M.G. Kang, J. Kang, S.Y. Park, S.J.C. Lee, H.T. Kim, J.K. Seo, O.H. Kwon, M.H. Lim, H.W. Rhee, T.H. Kwon, J. Am. Chem. Soc. 138 (2016) 10968-10977.

[104] K. Luby-Phelps, Mol. Biol. Cell 24 (2013) 2593-2596.

[105] R.E. Goldstein, J.-W. van de Meent, Interface Focus 5 (2015) 1-15.

[106] G. Dirk, U. Kutay, Annu. Rev. Cell Dev. Biol. 15 (1999) 607-660.

[107] Q. Zhao, S. Liu, M. Shi, C. Wang, M. Yu, L. Li, F. Li, T. Yi, C. Huang, Inorg. Chem. 45 (2006) 6152-6160.

[108] J. Liu, W. Bu, L. Pan, J. Shi, Angew. Chemie - Int. Ed. 52 (2013) 4375-4379.

[109] G. Zhang, H. Zhang, Y. Gao, R. Tao, L. Xin, J. Yi, Organometallics 33 (2014) 61-68.

[110] W. Tan, Q. Zhang, J. Zhang, H. Tian, Org. Lett. 11 (2009) 161-164.

[111] W. Zhu, X. Meng, Y. Yang, Q. Zhang, Y. Xie, H. Tian, Chem. - A Eur. J. 16 (2010) 899- 
906.

[112] F.J. Giordano, J. Clin. Invest. 115 (2005) 1-9.

[113] J. Biddlestone, D. Bandarra, S. Rocha, Int. J. Mol. Med. 35 (2015) 859-869.

[114] B. Muz, P. de la Puente, F. Azab, A.K. Azab, Hypoxia 3 (2015) 83-92.

[115] D. a. MacKenzie, A.R. Sherratt, M. Chigrinova, L.L.W. Cheung, J.P. Pezacki, Curr. Opin. Chem. Biol. 21 (2014) 81-88.

[116] G. Li, Q. Lin, L. Ji, H. Chao, J. Mater. Chem. B Mater. Biol. Med. 2 (2014) 7918-7926.

[117] M. Li, Y. Wang, Y. Yang, Y. Gao, M. Zhao, M. Zheng, S. Peng, Dalt. Trans. 44 (2015) $14071-14076$.

[118] A. Claude, Cold Spring Harb. Lab. Press (2015) 1-17.

[119] S. Gorski, J. Cell Sci. 118 (2005) 4083-4092.

[120] W. Jiang, Y. Gao, Y. Sun, F. Ding, Y. Xu, Z. Bian, F. Li, J. Bian, C. Huango, Inorg. Chem. 49 (2010) 3252-3260.

[121] M. Dundr, T. Misteli, Biochem. J. 356 (2001) 297-310.

[122] D. Hernandez-Verdun, P. Roussel, M. Thiry, V. Sirri, D.L.J. Lafontaine, Wiley Interdiscip. Rev. RNA 1 (2010) 415-431.

[123] K.Y. Zhang, H.W. Liu, T.T.H. Fong, X.G. Chen, K.K.W. Lo, Inorg. Chem. 49 (2010) 54325443.

[124] H. Ahmad, A. Wragg, W. Cullen, C. Wombwell, A.J.H.M. Meijer, J. a. Thomas, Chem. A Eur. J. 20 (2014) 3089-3096.

[125] D.J. Klionsky, S.D. Emr, Science (80-. ). 290 (2000) 1717-1721. 
[126] J.P. Luzio, P.R. Pryor, N. a Bright, Nat. Rev. Mol. Cell Biol. 8 (2007) 622-632.

[127] M. Ghosh, F. Carlsson, A. Laskar, X.M. Yuan, W. Li, FEBS Lett. 585 (2011) 623-629.

[128] M.E. Guicciardi, M. Leist, G.J. Gores, Oncogene 23 (2004) 2881-2890.

[129] U. Repnik, B. Turk, Mitochondrion 10 (2010) 662-669.

[130] L. Zhang, R. Sheng, Z. Qin, Acta Biochim Biophys Sin 41 (2009) 437-445.

[131] R. Hesselink, Biochim. Biophys. Acta - Mol. Basis Dis. 1637 (2003) 164-170.

[132] E.F. Neufeld, Annu. Rev. Biochem. 60 (1991) 257-280.

[133] W.R. Zipfel, R.M. Williams, W.W. Webb, Nat. Biotechnol. 21 (2003) 1369-1377.

[134] L. Zhu, W. Lv, S. Liu, H. Yan, Q. Zhao, W. Huang, Chem. Commun. 49 (2013) 1063810640.

[135] C.R. Berkers, F.W.B. van Leeuwen, T. a Groothuis, V. Peperzak, E.W. van Tilburg, J. Borst, J.J. Neefjes, H. Ovaa, Mol. Pharm. 4 (2007) 739-748.

[136] X. Zhu, W. Lu, Y. Zhang, A. Reed, B. Newton, Z. Fan, H. Yu, P.C. Ray, R. Gao, Chem. Commun. 47 (2011) 10311-10313.

[137] Y.M. Ho, N.P. Au, K.L. Wong, C.T. Chan, W.M. Kwok, G.L. Law, K.K. Tang, W.Y. Wong, C.H. Ma, M.H. Lam, Chem Commun 50 (2014) 4161-4163.

[138] L. He, S.Y. Liao, C.P. Tan, Y.Y. Lu, C.X. Xu, L.N. Ji, Z.W. Mao, Chem Commun 50 (2014) $5611-5614$.

[139] H. Yu, Y. Xiao, L. Jin, J. Am. Chem. Soc. 134 (2012) 17486-17489.

[140] J.R. Friedman, J. Nunnari, Nature 505 (2014) 335-343.

[141] S. a Detmer, D.C. Chan, Nat. Rev. Mol. Cell Biol. 8 (2007) 870-879. 
[142] J. Nunnari, A. Suomalainen, Cell 148 (2012) 1145-1159.

[143] S. Vyas, E. Zaganjor, M.C. Haigis, Cell 166 (2016) 555-566.

[144] R.J. Gillies, I. Robey, R. a Gatenby, J Nucl Med 49 Suppl 2 (2008) 24S-42S.

[145] S. Rodríguez-Enríquez, A. Marín-Hernández, J.C. Gallardo-Pérez, L. Carreño-Fuentes, R. Moreno-Sánchez, Mol. Nutr. Food Res. 53 (2009) 29-48.

[146] X. Ning, J. Guo, M. a. Wolfert, G.J. Boons, Angew. Chemie - Int. Ed. 47 (2008) 22532255.

[147] A.E. Wendlandt, S.S. Stahl, Angew. Chemie - Int. Ed. 54 (2015) 14638-14658.

[148] Z. Liu, R.J. Deeth, J.S. Butler, A. Habtemariam, M.E. Newton, P.J. Sadler, Angew. Chemie - Int. Ed. 52 (2013) 4194-4197.

[149] F.M. Veronese, Biomaterials 22 (2001) 405-417.

[150] Y. Hong, W.Y. Lam, B. Zhong, Chem. Commun. (2009) 4332-4353.

[151] D.P. Narendra, Nat. Rev. Mol. Cell Biol. 12 (2011) 9-14.

[152] M. Zanoni, F. Piccinini, C. Arienti, A. Zamagni, S. Santi, R. Polico, A. Bevilacqua, A. Tesei, Sci. Rep. 6 (2016) 1-11.

[153] M.H. Lee, N. Park, C. Yi, J.H. Han, J.H. Hong, K.P. Kim, D.H. Kang, J.L. Sessler, C. Kang, J.S. Kim, J. Am. Chem. Soc. 136 (2014) 14136-14142.

[154] S.J. Riedl, Y. Shi, Nat. Rev. Mol. Cell Biol. 5 (2004) 897-907.

[155] C. Jin, J. Liu, Y. Chen, L. Zeng, R. Guan, C. Ouyang, L. Ji, H. Chao, Chem. - A Eur. J. 21 (2015) 12000-12010.

[156] M.J. Phillips, G.K. Voeltz, Nat. Rev. Mol. Cell Biol. 17 (2015) 69-82. 
[157] D.S. Schwarz, M.D. Blower, Cell. Mol. Life Sci. 73 (2016) 79-94.

[158] C. Xu, B. Bailly-Maitre, J. Reed, J. Clin. Invest. 115 (2005) 2656-2664.

[159] A.H. Schönthal, Scientifica (Cairo). 2012 (2012) 857516.

[160] R.H. (Meyer M.H. McMenamy, J. Biol. Chem. 240 (1965) 4235-4243.

[161] A. Bertuzzi, G. Mlngrone, A. Gandolfi, A. V Greco, S. Ringoir, R. Vanholder, Clin. Chim. Acta 265 (1997) 183-192.

[162] R. Cao, J. Jia, X. Ma, M. Zhou, H. Fei, J. Med. Chem. 56 (2013) 3636-3644.

[163] X. Wang, J. Jia, Z. Huang, M. Zhou, H. Fei, Chem. - A Eur. J. 17 (2011) 8028-8032.

[164] A.R. English, G.K. Voeltz, Cold Spring Harb. Perspect. Biol. (2013) 1-16.

[165] N. Jacquier, V. Choudhary, M. Mari, A. Toulmay, F. Reggiori, R. Schneiter, J. Cell Sci. 124 (2011) 2424-2437.

[166] Q. Gao, J.M. Goodman, Front. Cell Dev. Biol. 3 (2015) 1-12. 